\title{
2014 Korean Guidelines for Appropriate Utilization of Cardiovascular Magnetic Resonance Imaging: A Joint Report of the Korean Society of Cardiology and the Korean Society of Radiology
}

\author{
Yeonyee E. Yoon, MD ${ }^{1 *}$, Yoo Jin Hong, MD ${ }^{2 *}$, Hyung-Kwan Kim, $\mathrm{MD}^{3}$, Jeong A Kim, MD ${ }^{4}$ Jin Oh Na, MD ${ }^{5}$, \\ Dong Hyun Yang, MD' ${ }^{6}$ Young Jin Kim, MD², and Eui-Young Choi, $\mathrm{MD}^{7}$ \\ 1 Department of Cardiology, Cardiovascular Center, Seoul National University Bundang Hospital, Seongnam, \\ ${ }^{2}$ Department of Radiology, Severance Hospital, Yonsei University College of Medicine, Seoul, \\ ${ }^{3}$ Division of Cardiology, Department of Internal Medicine, Cardiovascular Center, Seoul National University College of Medicine, Seoul National University Hospital, Seoul, \\ ${ }^{4}$ Department of Radiology, Ilsan Paik Hospital, Inje University College of Medicine, Goyang, \\ ${ }^{5}$ Cardiovascular Center, Korea University Guro Hospital, Korea University College of Medicine, Seoul, \\ ${ }^{6}$ Department of Radiology, Asan Medical Center, University of Ulsan College of Medicine, Seoul, \\ ${ }^{7}$ Division of Cardiology, Gangnam Severance Hospital, Yonsei University College of Medicine, Seoul, Korea
}

Cardiac magnetic resonance (CMR) imaging is now widely used in several fields of cardiovascular disease assessment due to recent technical developments. CMR can give physicians information that cannot be found with other imaging modalities. However, there is no guideline which is suitable for Korean people for the use of CMR. Therefore, we have prepared a Korean guideline for the appropriate utilization of CMR to guide Korean physicians, imaging specialists, medical associates and patients to improve the overall medical system performances. By addressing CMR usage and creating these guidelines we hope to contribute towards the promotion of public health. This guideline is a joint report of the Korean Society of Cardiology and the Korean Society of Radiology. (Korean Circ J 2014;44(6):359-385)

KEY WORDS: Guideline; Appropriateness criteria; Magnetic resonance imaging; Heart; Evidence-based medicine.

\section{Preface}

Cardiac magnetic resonance (CMR) imaging is now widely used in several fields of cardiovascular disease due to recent technical developments. For each clinical situation, physicians must choose the best imaging modality among echocardiography, cardiac computed tomography (CT), CMR or nuclear imaging. However, while each imaging modality has individual strengths in specific fields, previous studies have just focused on each modality's feasibility and strength separately. Regarding CMR, some guidelines for appropriate utilization have been published especially in Canada" or Europe. ${ }^{23)}$ However, ethnicity, socioeconomic status, clinical practice environment, and the medical insurance system are different from country to country. To overcome ethnic differences, the Asian Society of Cardiovascular Imaging (ASCI) published practice guidelines for CMR utilization in 2010.4) Even with this effort, differences in

Received: September 25, 2014 / Revision Received: October 17, 2014 / Accepted: October 19, 2014

Correspondence:

- Young Jin Kim, MD, Department of Radiology, Severance Hospital, Yonsei University College of Medicine, 50-1 Yonsei-ro, Seodaemun-gu, Seoul 120-752, Korea

Tel: 82-2-2228-7400, Fax: 82-2-393-3035,E-mail: dryj@yuhs.ac

- Eui-Young Choi, MD, Division of Cardiology, Gangnam Severance Hospital, Yonsei University College of Medicine, 211 Eonju-ro, Gangnam-gu, Seoul 135-720, Korea

Tel: 82-2-2019-3310, Fax: 82-2-2019-2314,E-mail: choi0928@yuhs.ac

*Two authors equally contributed.

- This guideline was developed through collaboration between the Korean Society of Cardiology and the Korean Society of Radiology and has been published jointly by invitation and consent in both the Korean Circulation Journal and the Korean Journal of Radiology.

- The authors have no financial conflicts of interest.

This is an Open Access article distributed under the terms of the Creative Commons Attribution Non-Commercial License (http://creativecommons.org/licenses/ by-nc/3.0) which permits unrestricted non-commercial use, distribution, and reproduction in any medium, provided the original work is properly cited. 
socioeconomic status and the medical insurance system have still not been fully overcome. In addition, more evidence has been collected from when the last guideline was published 4 years ago. Therefore, here, we have prepared a Korean guideline for the appropriate utilization of CMR to guide Korean physicians, imaging specialists, medical associates and patients so that the best possible practice of CMR is done.

\section{Methods for Establishing the 2014 Korean Guidelines for Appropriate Utilization of Cardiac Magnetic Resonance}

The guidelines presented here were conjointly established by the Korean Society of Cardiology (KSC) and the Korean Society of Radiology (KSR). The two Societies decided to do a guideline adaptation of pre-existing guidelines and guideline development was based on the (Adaptation Process for Developing Korean Clinical Practice Guidelines) published by the Ministry of Health and Welfare in November 2011. The Clinical Practice Guideline Executive Committee of the Korean Academy of Medical Sciences (KAMS) was consulted for guideline development methods and a library search expert participated during the development of the 2014 Korean Guidelines. The Writing Committee was comprised of 4 members appointed by the Cardiovascular Imaging Research Group of the KSC and 4 members appointed by the Korean Society of Cardiovascular Imaging of the KSR. The Delphi method was used to develop and establish guidelines in consensus. The Rating Committee for the Delphi consensus process was comprised of 20 panelists who were appointed by the KSR and the KSC. The Writing Committee made a first draft of the Korean CMR guidelines by consolidating pre-existing guidelines and related research study results selected for guideline adaptation and the Committee then prepared a questionnaire based on this first draft. The final guidelines were established with the outcomes found by panels of the Rating Committee through three rounds of the Delphi consensus process. For the development of the 2014 Korean guidelines, we reviewed pre-existing utilization guidelines from US, ${ }^{5)}$ Canada, ${ }^{1)}$ Europe ${ }_{1}^{2) 3}$ and Asia, ${ }^{4)}$ which were written in English. From national databases, 51 articles from the National Guideline Clearing House of the United States, 2 from the Scottish Intercollegiate Guidelines Network and 16 from the National Institute for Health and Care Excellence of the United Kingdom were reviewed. In addition, 54 articles from PubMed, 40 articles from the Cochrane Library, and 55 articles from Embase were reviewed. Only publications and guidelines from January 2000 to June 2013 were selected and reviewed. When guidelines had been revised, the most recent version of the guideline was selected for review. Guidelines that did not give detailed data on the utilization of CMR in relation to overall disease treatment or guidelines that were established by expert consensus without being supported by objective evidence were excluded. Six pre-existing guidelines were finally selected for guideline adaptation. To evaluate the quality of pre-existing guidelines selected for guideline adaptation, 4 of the Writing Committee members graded each guideline according to the Korean Appraisal of Guidelines for Research \& Evaluation II (K-AGREE II). An evaluation of pre-existing guidelines was made with the Korean Appraisal of Guidelines for Research \& Evaluation (K-AGREE) which was developed as a Korean version of AGREE 2.0 by the Clinical Practice Guideline Executive Committee of the KAMS. Four members of the Writing Committee evaluated the 6 selected pre-existing guidelines and a reevaluation was done of any category with a difference of more than 2 points. ${ }^{1-7)}$ A standardized score was found for each section and compared. Three guidelines that had standardized scores for rigour of development category greater than 50\% were finally chosen. However, these were guidelines for the diagnosis and treatment of specific diseases and as such, the guidelines for the utilization of CMR were limited to those specific medical conditions. Thus, 2 guidelines that had high standardized scores were selected additionally out of 3 guidelines regarding the indications of CMR. Tables for the K-AGREE evaluation results and guideline matrixes are given in the Supplement (in the online-only Data Supplement). Among the 5 guidelines selected for guideline adaptation, some did not present the level of evidence. As the level of evidence in some of the guidelines was thought to possibly be changed with more recent studies, additional papers were searched for each question. PubMed and Embase were used to search for supportive evidence and the searching parameters were restricted to publications between 2000 and 2013, studies done on humans only, and studies published in English. After developing appropriate searching formulas for each question, a review was done of the search results and evidential studies were selected for each related question. When a more recent systematic review or a meta-analysis study was found, papers previously published with lower levels of evidence were excluded along with case reports. Search formulas for each category are given in the Supplement (in the online-only Data Supplement).

The levels of evidence given in this guideline are stratified into 3 grades and are based on the levels of evidence for prognosis and diagnosis published by the Oxford Centre for Evidence-Based Medicine in 2011. A level of evidence, of either $A, B$, or $C_{1}$ is provided for each recommendation. The following table lists (Table 1 and 2 ) the levels of evidence and how the evidence was graded.

The appropriateness criteria was adapted from the 2010 American Heart Association cardiac CT appropriateness criteria and defined with three ratings: appropriate, uncertain, and inappropriate 
(Table 3). Throughout the guidelines, the criteria is marked with $A$ (Appropriate), U (Uncertain), or I (Inappropriate). ${ }^{8)}$

The questionnaire was based on a first draft of the Korean guidelines and had 4 sections with a total of 52 questions. A survey was conducted a total of 3 times, and for each question, the appropriateness of CMR utilization was graded with a response scale; 1-3 points defining the use of CMR as inappropriate, 4-6 points as uncertain, and 7-9 points as appropriate. When more than $70 \%$ of the panelists agreed on a grade, the panel was considered to have reached consensus for that particular section. The report form for the Delphi consensus included appropriateness criteria from other guidelines for each category, levels of evidence based on searched literature, the response scale (9-point scale), sections available for panelists to write in other comments, and a reference list for each question. In following consensus rounds, questions for which agreement had not been reached had both their median score from the previous round and the score given in the previous round by the answering panelist listed. Response sections of questions for which agreement had been reached in previous rounds were covered in the questionnaires in the following rounds. No modifications were made to questions for which agreement had not been reached in the previous round and no other comments were written down on the questionnaires by any of the panelists. Of a total of 52 questions, a consensus was reached on 47 questions in the first survey, 4 questions in the second survey, and 1 remaining question on the third survey. The response rate for each round was 100\%. The results

Table 1. Definition of levels of evidence

\begin{tabular}{cl}
\hline Level of evidence & Definition \\
\hline A & Level 1 study, two or more Level 2 studies \\
B & One Level 2 study, two or more Level 3 studies \\
C & One Level 3 study, Level 4 or 5 study \\
\hline
\end{tabular}

of the Delphi voting are included in the Supplement (in the onlineonly Data Supplement).

A total of 10 members, consisting of 1 member of the Clinical Practice Guideline Executive Committee of the KAMS, 3 of the KSC, 3 of the Korean Pediatric Heart Association, and 3 of the KSR, reviewed the guidelines selected by consensus, which were later verified at an independent audit forum. The development of the current guidelines was funded by the KSC and KSR. However, the activities of the Writing Committee, the Rating Committee for the Delphi consensus and the Reviewing Committee that reviewed and verified the selected recommendations were independent of one another and none of the three Committees were influenced by any of the Societies funding the guideline development.

These recommendations should be revised every $3-5$ years, depending on the development of magnetic resonance imaging (MRI) technology, changes in the healthcare environment, and further accumulation of evidence associated with CMR.

\section{Contents}

\section{Detection of coronary artery disease: symptomatic}

\section{Clinical scenario 1: evaluation of chest pain syndrome}

There are several approaches to detect coronary artery disease (CAD) using CMR. These include direct visualization of coronary arteries using MR coronary angiography, and visualization of the effects of induced ischemia using stress CMR imaging. Stress CMR imaging can be performed with 2 different techniques: 1) dynamic first-pass perfusion imaging, which assesses inducible perfusion defects, indicative of impaired perfusion reserves; and 2) stress-inducible wall motion abnormalities imaging, which evaluates the impairment of regional endocardial excursion and myocardial thickening,

Table 2. Definition of levels of study

\begin{tabular}{cl}
\hline Level of study & Definition \\
\hline 1 & Systematic review, meta-analysis \\
2 & Individual cross sectional studies with consistently applied reference standard and blinding/Inception cohort studies \\
3 & Non-consecutive studies, or studies without consistently applied reference standards/Cohort study or control arm of randomized trial \\
4 & Case-control studies, or poor or non-independent reference standard/Case-series or case-control studies, or poor quality prognostic cohort study \\
5 & Mechanism-based reasoning \\
\hline
\end{tabular}

Table 3. Definition of appropriateness criteria

\begin{tabular}{ll}
\hline Appropriateness criteria (score) & Definition \\
\hline A-Appropriate (7-9) & Test is generally acceptable and a reasonable approach for the listed indication. \\
U-Uncertain (4-6) & $\begin{array}{c}\text { Test may be generally acceptable and may be a reasonable approach for the indication. Uncertainty also implies } \\
\text { that more patient evaluation or patient information is needed to classify the indication definitively. }\end{array}$ \\
\hline I-Inappropriate (1-3) & Test is not generally acceptable and is not a reasonable approach for the indication. \\
\hline
\end{tabular}


also indicative of underlying ischemia.

\section{Myocardial perfusion imaging}

Cardiac magnetic resonance perfusion imaging is performed using a T1-weighted sequence to visualize the first passage of a gadolinium based contrast agent in transit through the heart. Following the intravenous injection, the contrast is detected against a background of nulled myocardium with rapid enhancement with and without vasodilation stress. Signal intensity correlates with contrast concentration, and analysis can be performed in a quantitative, semi-quantitative, or qualitative fashion. Visual interpretation is usually performed to identify dark areas of hypoperfusion relative to normally perfused segments. Semi-quantification can be performed by measuring the upslope of myocardial signal increase. ${ }^{9)}$ Deconvolution analysis allowing for the input function from the left ventricular (LV) blood pool signal curve can be used to generate regional values for the quantitative perfusion index and myocardial perfusion reserve. ${ }^{10)}$

Validation of CMR perfusion imaging in humans has been performed in a number of clinical studies employing a variety of contrast agents, analysis techniques, and reference standards. ${ }^{11-15)} \mathrm{A}$ meta-analysis of CMR perfusion studies demonstrated a sensitivity of $91 \%$ and a specificity of $81 \%$ for the diagnosis of CAD with $\geq 50 \%$ diameter stenosis using catheter-based $X$-ray coronary angiography (XCA) as a reference standard. ${ }^{16)}$ The Magnetic Resonance Imaging for Myocardial Perfusion Assessment in Coronary Artery Disease Trial (MR-IMPACT) study of 241 patients compared the diagnostic performance of CMR perfusion imaging and single photon emission computed tomography (SPECT) and reported a similar overall accuracy. ${ }^{14)}$ In a subsequent larger multicenter trial, MR-IMPACT II, of 533 patients, comparing CMR perfusion to SPECT suggests a higher sensitivity (75\% vs. 52\%, respectively) and lower specificity of CMR perfusion (59\% vs. 72\%, respectively). ${ }^{15)}$ When the investigators performed receiver operator characteristics curve analysis, the diagnostic performance estimated as area under the curve of CMR perfusion is superior to SPECT. ${ }^{17)}$ However, there was a trend towards slightly lower sensitivity and specificity in the MR-IMPACT II study compared to the MR-IMPACT I study (75\% vs. 85\%, respectively; $59 \%$ vs. $67 \%$, respectively). This might be related to the larger number of sites participating in the MR-IMPACT II study, in which less experienced centers might have contributed more to the database. Although CMR perfusion is currently thought to be an alternative to SPECT to detect perfusion deficit in CAD, appropriate physician and staff training and a facility capable of performing the stress test are required.
Stress imaging of ventricular function

Cardiac magnetic resonance can detect myocardial ischemia using exercise and pharmacological stressors with an accuracy comparable to nuclear imaging and echocardiography. ${ }^{18-24)} A$ metaanalysis of stress-functional CMR studies demonstrated a sensitivity of $83 \%$ and a specificity of $86 \%$ for the demonstration of CAD with $\geq 50 \%$ diameter stenosis using catheter-based $X C A$. ${ }^{16)}$ Since physical exercise is difficult to perform within the magnet bore and often induces motion artifacts, pharmacological stress is more commonly used. Dobutamine with and without atropine is the most common stressor used for assessment of inducible wall motion abnormalities. ${ }^{18-22(24) 25)}$ Breath-hold gradient echo or steady state free precession (SSFP) cines are used to examine regional wall function throughout the LV before and during stress as the dose of dobutamine is increased in a similar manner to dobutamine stress echocardiography. Dobutamine stress CMR has a high accuracy for detecting ischemia, related in part to excellent LV endocardial visualization throughout dobutamine/atropine stress protocols. ${ }^{20)}$ Thus, dobutamine CMR appears to be valuable for patients who are unsuitable for dobutamine echocardiography. ${ }^{19)}$ Dobutamine stress CMR exhibits major complications (i.e., the development of sustained ventricular tachycardia) in less than $0.1 \%$ of subjects, findings that are similar to those observed with dobutamine stress echocardiography. ${ }^{26)}$

Other CMR techniques have been used to assess CAD with dobutamine. Tagging methods have shown increased sensitivity for CAD diagnosis. ${ }^{27)}$ Strain quantification using strain-encoded CMR allows early detection of inducible ischemia during intermediate stage. ${ }^{28)}$ Real-time CMR may be used to monitor wall motion and may eliminate the need for breath-holding. ${ }^{24)}$ However, further studies are required to determine the clinical role of these imaging techniques.

\section{Magnetic resonance coronary angiography}

Magnetic resonance coronary angiography is technically more challenging than MR angiography of other vascular beds due to the small caliber, tortuosity, and complex motion of the coronary arteries during the cardiac cycles, and the surrounding signal from adjacent epicardial fat and myocardium. To overcome these obstacles, several CMR approaches are employed. Cardiac triggering \{e.g., vector electrocardiogram (ECG) $\}$ is used to account for intrinsic cardiac motion. Although breath-holding can be used to suppress respiratory motion, it has limited applicability of MR coronary angiography. Navigator echo method can be used for respiratory gating and enables free-breathing MR coronary angiography. Bright blood technique (segmented gradient echo and SSFP) is commonly used without a contrast agent, and pre-pulses (e.g., fat saturation, T2 preparation) are used to enhance the contrast-to-noise ratio of the coronary arterial blood. Recently, target-volume approach has been 
largely replaced by the whole-heart MR coronary angiography which allows visualization of all major coronary arteries with a single axial three-dimensional (3D) acquisition in a similar manner to that for CT coronary angiography.

Several studies evaluated the diagnostic performance of MR coronary angiography for detecting significant $C A D{ }^{29-34)} A$ prospective multicenter, free-breathing, 3D volume-targeted MR coronary angiography study demonstrated a very high sensitivity (100\%) and a modestly high specificity (85\%) with a very high negative predictive value (100\%) of MR coronary angiography for the identification of left main and multi-vessel CAD. ${ }^{29)}$ In a recent prospective multicenter study, SSFP whole-heart MR coronary angiography demonstrated a high sensitivity (88\%) and moderate specificity (72\%) with a high negative predictive value (88\%) in the detection of significant CAD. ${ }^{31)}$

Clinical utilization of MR coronary angiography has been limited for the detection of CAD, mainly due to low spatial resolution and long imaging time. However, substantial progress in imaging hardware and techniques has been made during past decades. The introduction of 32-channel cardiac coils permits use of higher parallel imaging acceleration factors and substantially reduces the imaging time of MR coronary angiography within 10 minutes. ${ }^{35)}$ The higher field, 3-T system provides better signal and contrast values relative to the 1.5-T system, and thus, may improve the detection of CAD with MR coronary angiography. ${ }^{32)}$ A recent comparison study of 3-T MR coronary angiography with 32-channel cardiac coils and 64-slice CT demonstrated similar diagnostic accuracy between the two techniques. ${ }^{33)}$ However, to date, data regarding the clinical utility of MR coronary angiography for the evaluation of CAD are based on high-risk populations referred for catheter-based XCA. And, importantly, the majority of MR coronary angiography data has been generated in only a few highly specialized centers.

\section{Cardiac magnetic resonance for prognosis assessment}

Prognostic data are now available using both vasodilator and dobutamine stress functional CMR methods. ${ }^{36-39)}$ In a recent metaanalysis, the annualized event rates for composite outcome of cardiovascular death and myocardial infarction were 4.9\% for positive versus $0.8 \%$ for a negative stress $\mathrm{CMR}^{39}{ }^{39}$ Another meta-analysis demonstrated a high negative predictive value of $98 \%$ for cardiac death and myocardial infarction of negative stress CMR, and showed a similar ability to identify low-risk patients with known or suspected CAD. ${ }^{38)}$ In patients with suspected or known CAD, stress CMR has excellent prognostic value and may help guide risk stratification. However, data on prognostic value of MR coronary angiography is limited. Only a recent single study, including 207 patients with suspected $C A D$, reported that significant stenosis detected by MR cor- onary angiography can be used to identify patients at high risk for subsequent adverse cardiac events, whereas normal MR coronary angiography results are associated with a very low event rate. ${ }^{40)}$

\section{Detection of CAD: symptomatic}

Evaluation of chest pain syndrome (protocols may include vasodilator perfusion CMR, dobutamine stress function CMR, and/or MR coronary angiography)

1. Low pre-test probability of CAD/ECG interpretable AND able to exercise (Level of evidence: A, Appropriateness criteria: I)

2. Intermediate pre-test probability of CAD/ECG interpretable AND able to exercise (Level of evidence: A, Appropriateness criteria: U)

3. Intermediate pre-test probability of CAD/ECG interpretable AND able to exercise (Level of evidence: A, Appropriateness criteria: A)

4. High pre-test probability of CAD (Level of evidence: A, Appropriateness criteria: U)

\section{Clinical scenario 2: evaluation of coronary artery anomaly (use of} magnetic resonance coronary angiography)

Coronary artery anomalies are a diverse group of congenital disorders with manifestations and pathophysiological mechanisms that are highly variable. Although the majority of coronary artery anomalies are not thought to be hemodynamically significant, anomalous origination of a coronary artery from the opposite sinus with subsequent passage between the aorta and pulmonary artery is a well-recognized cause of myocardial ischemia and sudden cardiac death in young individuals. ${ }^{41)}$ Traditionally, catheter-based XCA has been used to identify these anomalies. However, XCA only provides a two-dimensional (2D) view, thus the complex 3D course of the anomalous vessel, especially in respect to the aorta and pulmonary artery, may be difficult to discern. Furthermore, the presence of an anomalous vessel is sometimes only suspected even after an invasive angiography, because of an unsuccessful engagement and visualization of the coronary artery. CT coronary angiography and MR coronary angiography are alternatives to XCA, which are noninvasive and have the multi-planar capability of providing $3 \mathrm{D} \mathrm{im-}$ ages. MR coronary angiography has several significant advantages over XCA and CT coronary angiography for diagnosing coronary artery anomalies: MR coronary angiography does not expose patients to ionizing radiation and can be performed without administration of contrast agents at 1.5-T. This is an important consideration especially in adolescents and younger adults with suspected anomalous CAD. Both 2D breath-hold and targeted 3D or free-breathing 
navigator whole-heart MR coronary angiographic methods have been used with similar excellent results. However, 3D whole-heart MR coronary angiography with a single axial 3D acquisition has become the method of choice for MR coronary imaging, and is thought to have marked utility relative to the $2 \mathrm{D}$ projection technique in the assessment of coronary artery anomalies. ${ }^{42-47)}$

\section{Evaluation of intracardiac structures (use of MR coronary angiography)}

1. Evaluation of suspected coronary anomalies (Level of evidence: B, Appropriateness criteria: A)

\section{Clinical scenario 3: acute chest pain}

The use of CMR in the emergency department may allow for a more rapid and comprehensive evaluation of patients. The unique advantage of CMR imaging is that it can provide information on myocardial function, perfusion, and infarction in a single scanning session. However, to date, there is a paucity of data regarding the utility of CMR in the triage of acute chest pain patients. By combining the assessment of the left ventricular function, adenosine stress perfusion, and late gadolinium enhancement (LGE) imaging, CMR demonstrated a sensitivity of $96 \%$ and a specificity of $83 \%$ for the detection of significant stenosis in 68 patients with non-STsegment elevation myocardial infarction. ${ }^{48)}$ Otherwise, there have only been 2 small single-center observational trials in patients with acute chest pain and an inconclusive evaluation in the emergency department. CMR including the LV function, resting perfusion, and LGE imaging was performed in 161 patients with acute chest pain and showed a sensitivity of $84 \%$ and a specificity of $85 \%$, respectively. ${ }^{49)}$ In a smaller study with 62 patients, the addition of the T2weighted sequence for the detection of myocardial edema improved the specificity and positive predictive value for acute coronary syndrome to $96 \%$ and $85 \%$. $^{50)}$ Management of intermediate-risk patients with possible acute coronary syndrome in an observational unit with CMR may reduce medical costs during the index visit and subsequent to discharge over the first year. ${ }^{51)}$ The reduction in costs even after discharge is thought to be associated with fewer coronary artery revascularizations, fewer hospital readmissions, and fewer cases of recurrent cardiac testing. ${ }^{52)}$ However, as with the diagnostic accuracy literature for CMR, studies in this area are primarily single-center reports that describe the findings of experienced observers in a small number of patients. Thus, at present, the level of evidence is low, and larger multicenter investigations should further build on these results.

\section{Acute chest pain (protocols may include vasodilator perfusion CMR or dobutamine stress function CMR)}

1. Low pre-test probability of CAD/No ECG changes and serial cardiac enzyme negative (Level of evidence: A, Appropriateness criteria: U)

2. Intermediate pre-test probability of CAD/No ECG changes and serial cardiac enzyme negative (Level of evidence: $A_{\text {, }}$ Appropriateness criteria: U)

3. High pre-test probability of CAD/No ECG changes and serial cardiac enzyme negative (Level of evidence: A, Appropriateness criteria: U)

4. High pre-test probability of CAD/ECG-ST-segment elevation and/or positive cardiac enzymes (Level of evidence: $A_{\text {, }}$ Appropriateness criteria: I)

\section{Clinical scenario 4: detection of coronary artery disease with prior test results}

An important decision facing clinicians is whether a noninvasive cardiac imaging result warrants revascularization or whether medical management is most appropriate. Current guidelines recommend proof of ischemia prior to elective revascularization. ${ }^{53-55)} \mathrm{How}$ ever, the severity of coronary stenosis assessed by catheter-based XCA or CT coronary angiography does not correlate well with functional significance assessed by the fractional flow reserve (FFR). ${ }^{56}$ The relevance of this discrepancy has been highlighted by results of the Fractional Flow Reserve versus Angiography for Multivessel Evaluation (FAME) trial, which demonstrated improved cardiac outcome when FFR measurements were taken during coronary intervention for multi-vessel disease. ${ }^{57(58)}$ These results show the importance of assessing the functional significance of CAD in addition to anatomic evaluation, supporting the use of noninvasive testing for guiding revascularization.

Stress CMR, either with vasodilator or dobutamine stress, has been shown to have high diagnostic accuracy for the detection of significant CAD. ${ }^{13-16) 59)}$ Several studies have compared stress CMR perfusion imaging with the invasive reference standard, FFR, and have demonstrated good correlation between stress CMR perfusion imaging and FFR. ${ }^{60-63)}$ In a single center study by Watkins et al, ${ }^{62)} 103$ patients with suspected angina underwent stress CMR perfusion imaging and catheter-based XCA and FFR was measured in all major patent epicardial coronary arteries. Stress CMR perfusion imaging can detect functionally significant CAD defined as FFR $<0.75$ with excellent sensitivity (91\%), specificity (94\%), and positive and negative predictive values ( $91 \%$ and $94 \%$, respectively). In a recent study by Groothuis et $\mathrm{al}_{1}{ }^{64)}$ the addition of stress CMR perfusion 
imaging to CT coronary angiography significantly improved specificity and overall diagnostic accuracy for the detection of significant CAD as defined by catheter-based XCA with conditional FFR measurement. Thus, in clinical practice, stress CMR can subsequently be used to assess the hemodynamic significance of CAD and to direct revascularization. Stress CMR provides excellent prognostic stratification of patients with known or suspected CAD with a high negative predictive value for adverse cardiac events. ${ }^{38 / 39}$ Further, it has a number of advantages over the other noninvasive techniques, including high spatial and temporal resolution, no exposure to ionizing radiation, no attenuation or scatter artifacts, and no image orientation constraints. However, it is currently difficult to conclude that using ischemic burden to guide the decision for revascularization with stress CMR is superior compared to other noninvasive tests. Although a few previous studies have reported a higher diagnostic accuracy of stress CMR in comparison to myocardial SPECT, the majority of studies have compared diagnostic accuracy for the detection of significant $C A D$, using catheterbased XCA as the reference standard..$^{13-15) 1765)}$ It needs to be confirmed whether stress CMR guided revascularization truly achieves a therapeutic reduction in ischemia or truly improves outcomes.

Combining stress perfusion and wall motion assessment with LGE and/or coronary artery anatomy may further increase the diagnostic and prognostic power of stress CMR. In a large prospective study entitled Cardiovascular Magnetic Resonance and Single-photon Emission Computed Tomography for Diagnosis of Coronary Heart Disease (CE-MARC), multiparametric CMR including LV function, stress perfusion, LGE, and MR coronary angiography, demonstrated superior diagnostic accuracy compared to SPECT. ${ }^{13)}$ However, further studies are necessary to determine whether LGE or MR coronary angiography provides incremental information to stress CMR in the decision making process for revascularization.

\section{Detection of CAD: with prior test results (protocols may include vasodilator perfusion CMR or dobutamine stress function (MR)}

1. Normal prior stress test (exercise, nuclear, echo, MRI)/high $\mathrm{CHD}$ risk (Framingham)/within 1 year of prior stress test (Level of evidence: A, Appropriateness criteria: I)

2. Equivocal stress test (exercise, stress SPECT, or stress echo)/ intermediate CHD risk (Framingham) (Level of evidence: $A$, Appropriateness criteria: U)

3. Coronary angiography (catheterization or CT)/stenosis of unclear significance (Level of evidence: C, Appropriateness criteria: A)
Clinical scenario 5: evaluation of coronary artery disease in patients with post percutaneous coronary intervention or coronary artery bypass grafting

Several studies had reported that 10\% of postoperative grafts had been occluded either during or immediately after coronary artery bypass grafting (CABG). Moreover, in a 10 year follow-up study after the surgery, $59 \%$ of vein grafts and $17 \%$ of artery grafts had been occluded. ${ }^{66-68)}$ Therefore, reliable diagnostic methods for patency assessment are needed after CABG. Cardiac CT and CMR are noninvasive methods geared toward this end. Some studies have shown that high-resolution MR angiography provides fair diagnostic accuracy in evaluating the severity of vein graft stenosis comparing with invasive coronary angiography in patients with recurrent chest pain or in asymptomatic patients after bypass surgery. ${ }^{6970)}$ However, until now, most studies used cardiac CT to assess graft vessel patency after CABG and only a small number of studies utilized CMR for this purpose. Therefore, further studies on CMR in this capacity are warranted.

Regular clinical evaluation of stent restenosis is recommended in patients who have undergone percutaneous coronary intervention (PCI) with stent placement. ${ }^{55)}$ Although several studies had suggested that CMR imaging of coronary stents is a safe and promising non-invasive method that assessing patency of the coronary stents, ${ }^{71-73)}$ the use of MR coronary angiography for this purpose is limited by low-signal artifacts that occur at the stenting site and direct evaluation of in-stent restenosis is not possible. Therefore, MR coronary angiography is not recommended as an appropriate method for the routine evaluation of in-stent restenosis. Also, the indirect approach of inferring the degree of stenosis through the presence of distal flow turbulence has been known to have little credibility. ${ }^{7475)}$

\section{Evaluation of CAD: post $\mathrm{PCl}$ or $\mathrm{CABG}$}

Evaluation of chest pain syndrome (use of MR coronary angiography)

1. Evaluation of bypass grafts (Level of evidence: $C_{1}$ Appropriateness criteria: $\mathrm{U})$

2. History of percutaneous revascularization with stents (Level of evidence: C, Appropriateness criteria: I)

Asymptomatic (use of MR coronary angiography)

1. Evaluation of bypass grafts and coronary anatomy (Level of evidence: C, Appropriateness criteria: I)

2. Evaluation for in-stent restenosis and coronary anatomy after PCI (Level of evidence: C, Appropriateness criteria: I) 
Clinical scenario 6: coronary artery disease risk assessment: preoperative evaluation

The decision to conduct a preoperative cardiac evaluation is made based on the surgery-specific cardiac risk and patients scheduled for low-risk surgery can proceed to the surgery without further testing. However, when an intermediate- to high-risk surgery is scheduled, for which the risk of a myocardial infarction or cardiac mortality is around $5 \%$, additional cardiac evaluation may be necessary. ${ }^{7-80)}$ Additional heart tests are required when three or more clinical risk factors are present or when patient's functional capacity is poor. Because there is an increased risk associated with surgery, a noninvasive cardiac stress test is recommended before surgery. ${ }^{7677) 811}$

As a noninvasive preoperative cardiac testing method, CMR has the advantages of providing superior spatial and temporal resolution without exposure to harmful radiation in contrast to cardiac CT or myocardial perfusion scintigraphy, and of having more precision in cardiac evaluation than echocardiography in case with a poor acoustic window. Therefore, CMR has recently been used more frequently in clinical practice as a preoperative test for myocardial viability and perfusion, valvular heart disease, cardiomyopathy, and congenital heart disease ${ }^{82)}$ In particular, in patients who showed a negative stress perfusion CMR examination, the probability of not experiencing cardiac death or a nonfatal myocardial infarction for at least 3 years is as high as 99.2\%, indicating a very low likelihood of future cardiovascular disease. ${ }^{37)}$ Additionally, in meta-analysis of 21 studies that observed a total of 1233 subjects, stress perfusion CMR examination scored high on its ability to assess obstructive CAD with a sensitivity of $84 \%$ (range, 44-93\%) and a specificity of 80\% (range, 60-100\%); therefore, CMR is thought to be very useful in the preoperative assessment of CAD. ${ }^{37 / 83)}$ Furthermore, CMR is known for its excellence in assessing the LV ejection fraction and LV volume, which predicts the occurrence of postoperative heart failure. However, a disadvantage that must be mentioned is the difficulty of performing a CMR examination in patients with an artificial pacemaker, implantable defibrillator, or insulin pump. Thus, the patient's condition should be taken into account when performing CMR

\section{CAD risk assessment: preoperative evaluation (protocols may include vasodilator perfusion CMR or dobutamine stress function (MR)}

1. Low-risk non-cardiac surgery in patients with intermediate perioperative risk predictors (Level of evidence: $C_{1}$ Appropriateness criteria: I)

2. Intermediate or high risk non-cardiac surgery in patients with intermediate perioperative risk predictors (Level of evidence: C, Appropriateness criteria: $U$ )

3. CAD evaluation before valve surgery (Level of evidence: $C_{\text {, }}$ Appropriateness criteria: U)

Clinical scenario 7: evaluation of coronary artery disease:

in pediatric patients with Kawasaki disease

Echocardiography is the bedside technique of choice during the acute phase of the disease. CMR can be a valuable tool especially in children and adolescents, where sometimes echocardiography fails to detect coronary abnormalities and it has also the advantage of simultaneous perfusion, function and viability evaluation. If CMR is not available, a combination of echocardiography and SPECT gives an overview of anatomy, function and perfusion. Cardiac CT is of limited value for follow-up because of radiation and the misleading data due to coronary calcifications. Catheter-based XCA is kept mainly for cases where an invasive procedure should be performed. ${ }^{84)}$ Mavrogeni et al. ${ }^{8586)}$ compared the results of MR coronary angiography with XCA in a pediatric population. ${ }^{877}$ In the 6 patients, aneurysms of the coronary arteries were identified, while coronary ectasia alone was present in the remaining seven patients. MR coronary angiography and XCA diagnosis of coronary artery aneurysm (CAA) agreed completely. Maximal aneurysm diameter and length and ectasia diameter by MRA and XCA were similar. No stenotic lesion was identified by either technique. Another prospective study compared MR coronary angiography and XCA findings in patients with CAAs. There was complete agreement between MR coronary angiography and XCA in the detection of CAA $(n=11)$, coronary artery stenoses $(n=2)$, and coronary occlusions $(n=2)$. Excellent agreement was found between the 2 techniques for detection of CAA maximal diameter (mean difference $=0.4 \pm 0.6 \mathrm{~mm}$ ) and length (mean difference= $1.4 \pm 1.6 \mathrm{~mm}$ ). The 2 methods showed very similar results for proximal coronary artery diameter and CAA distance from the ostia. ${ }^{88)}$

Evaluation of CAD: in pediatric patients with Kawasaki disease (use of MR coronary angiography)

Asymptomatic

1. No previous definitive test (catheterbased XCA, MR coronary angiography, or CT coronary angiography) available (Level of evidence: $\mathrm{B}$, Appropriateness criteria: $U$ )

2. Previous tests (catheter-based XCA, MR coronary angiography, or CT coronary angiography) documented coronary aneurysm/stenosis, for follow-up (Level of evidence: B, Appro- 
priateness criteria: A)

Symptomatic

1. No previous definitive test (catheterbased XCA, MR coronary angiography, or CT coronary angiography) available (Level of evidence: B, Appropriateness criteria: A)

2. Previous tests (catheter-based XCA, MR coronary angiography, or CT coronary angiography) documented coronary aneurysm/stenosis, for follow-up (Level of evidence: B, Appropriateness criteria: A)

\section{Clinical scenario 8: detection of coronary artery disease:}

\section{asymptomatic}

Regarding role of CMR for detecting occult CAD, no well controlled studies have been reported. Especially, no efficacy data have been reported regarding "screening" MR coronary angiography in high-risk populations. Although other imaging modalities such as coronary calcium scoring has some evidences for risk stratifications in asymptomatic populations, CMR based stress perfusion study or MR coronary angiography based CAD detection need evidence to get any appropriateness levels. Therefore in this category of patients, performing CMR is not generally recommended in low- or intermediate-risk populations. Regarding in high risk asymptomatic populations, experts' recommendations from $\mathrm{ASCl}$ provide uncertain level with scoring 6, which means it may be a "reasonable approach"4)89)

\section{Detection of CAD: asymptomatic (protocols may include vasodilator perfusion $C M R$, dobutamine stress function CMR, and/or MR coronary angiography)}

1. Low CHD risk (Framingham) (Level of evidence: $A_{1}$ Appropriateness criteria: I)

2. Moderate CHD risk (Framingham) (Level of evidence: $A, A p-$ propriateness criteria: U)

3. High CHD risk (Framingham) (Level of evidence: A, Appropriateness criteria: U)

\section{Clinical scenario 9: detection of myocardial scar and viability} in ischemic heart disease

In patients with ischemic heart disease, discrimination of unviable necrotic areas from a viable area such as a stunned myocardium is important in the prediction of the potential recoverability of myocardial contractility and in the planning of future treatment directions. Contrast-enhanced CMR that uses gadolinium has been reported to be useful in the evaluation of myocardial viability by many studies. Contrast-enhanced CMR can also be performed on myocardial infarction patients before coronary artery revascularization to predict the post-procedural reversibility of myocardial contractility. ${ }^{9091)}$ A recent meta-analysis that evaluated the ability of LGE CMR to discern stunned myocardium that may be reversible in patients with myocardial infarction scheduled for coronary revascularization reported sensitivity of $87 \%$, a specificity of $68 \%$, a positive predictive value of $83 \%$, and a negative predictive value of $72 \%$, for an overall diagnostic accuracy of $82 \%$ in those surveyed. The dobutamine stress CMR technique was also evaluated and was found a sensitivity of $67 \%$, a specificity of $81 \%$, a positive predictive value of $82 \%$, a negative predictive value of $63 \%$, and an overall diagnostic accuracy of $74 \%$. Therefore, CMR was founded to be useful in the evaluation of myocardial viability. ${ }^{92)}$ Furthermore, in a meta-analysis of 4438 CAD patients, when the CMR examination detected LGE lesions, patients had a 2.65 \{95\% confidence interval (CI), 1.983.56 \} greater risk of developing major cardiovascular events (MACE), and a relationship to the size of the LGE in the lesion was found with every $10 \%$ of the LV affected leading to a $56 \%(95 \% \mathrm{Cl}, 1.39$ 1.75) increase in MACE development. These reports support the useful prognostic value of CMR in predicting MACE in patients with prior myocardial infarction. ${ }^{93)}$ Thus, based on reports of its usefulness in patients scheduled for coronary revascularization, CMR has become a recognized pre-procedural assessment method of the viability of cardiac function recovery.

Many studies have reported that dobutamine stress CMR and LGE CMR are important in the evaluation of myocardial viability. In particular, Romero et al. ${ }^{94)}$ reported in a meta-analysis of 24 studies including 698 patients, that LGE CMR scored high with a sensitivity and negative predictive value of 95\% and 90\%, respectively, and that dobutamine stress CMR scored 91\% and 93\% on specificity and positive predictive value, respectively. They therefore concluded that a more accurate prediction of cardiac function after coronary revascularization can be achieved by analyzing the results of several studies. $^{94-96)}$

Late gadolinium enhancement CMR was also compared to other noninvasive tests for myocardial viability, such as dobutamine stress echocardiography and SPECT. First, when comparing SPECT to $C M R$, while there was no significant difference in each method's ability to detect myocardial transmural necrosis or normal myocardium, LGE CMR was superior to SPECT in the detection of subendocardial infarction owing to its superior spatial resolution. ${ }^{97-99)}$ In addition, a recent prospective study has shown that CMR has a sensitivity of $86.5 \%$ and a specificity of $83.4 \%$ in the detection of CAD, which are superior to the $66.5 \%$ sensitivity and $82.6 \%$ specificity reported for SPECT. ${ }^{13)}$ Likewise, CMR appears to be superior to 
dobutamine stress echocardiography, which is known to have a similar overall accuracy to that of SPECT on the basis of a metaanalysis that compiled 11 studies and reported a sensitivity of 79\% and specificity of $87 \%{ }^{100)}$ Taken together, these results indicate that stress CMR has a special significance for patients who tested negative for low to moderate risk of CAD and for patients who tested positive for a high risk of CAD. CMR has therefore been shown to be effective for patients who tested as being moderately at risk by other noninvasive examination methods. ${ }^{16)}$

As previously described, it is known that LGE CMR is a good method for evaluating the size of myocardial necrosis prior to coronary revascularization and for determining whether or not myocardial necrosis after coronary revascularization is likely to occur and to what extent. When observing patients scheduled for $\mathrm{PCl}$, an increase in post-procedural troponin I level has been reported to show a strong positive correlation to the area of new myocardial enhancement as detected by LGE CMR. Moreover, in patients with an elevated level of creatinine kinase-MB, which indicates necrosis of the myocardium, LGE could be observed in structurally associated parts, indicating that it is possible to check for incidence of immediate post-procedural myocardial infarction. ${ }^{101)}$ Based on their research studies on acute ST elevated myocardial infarction patients, Eitel et al. ${ }^{101) 102)}$ concluded that the myocardial salvage index measured by CMR is related to the incidence of long-term MACE such as cardiac death and that it is therefore an important independent prognostic factor. Thus, it is believed that the implementation of CMR after coronary revascularization procedures can help assess the incidence of myocardial injury and that CMR can find further application as an indicator of patient prognosis. ${ }^{103)}$

Detection of myocardial scar and viability (protocols may include LGE evaluation or dobutamine stress function CMR)

1. To determine the location and extent of myocardial necrosis including 'no reflow' regions/post-acute myocardial infarction (Level of evidence: A, Appropriateness criteria: A)

2. To detect post PCI myocardial necrosis (Level of evidence: $A_{\text {, }}$ Appropriateness criteria: A)

3. To determine viability prior to revascularization/establish likelihood of recovery of function with revascularization $(\mathrm{PCl}$ or $C A B G$ ) or medical therapy (Level of evidence: A, Appropriateness criteria: $A)$

4. To determine viability prior to revascularization/viability assessment by SPECT or dobutamine echo has provided "equivocal or indeterminate" results (Level of evidence: A, Appropriateness criteria: A)

\section{Structure and myocardial functional evaluation in patients with risk of heart failure or overt heart failure}

\section{Clinical scenario 10: evaluation in patients with risk of heart failure or overt heart failure (general)}

The main symptoms of heart failure include shortness of breath, fatigue, and exercise intolerance, resulting from variable combinations of fluid retention in the body and significant decline in tissue perfusion. ${ }^{104)}$ Physical examination in heart failure patients can reveal cardiac murmur, jugular venous engorgement, pedal edema, crackles, and/or cold extremities, depending on the heart failure severity. ${ }^{104)}$ Heart failure is characterized by an abnormality of cardiac structure and/or function, leading to the impairment of the heart ability to meet the oxygen requirements of the tissues. ${ }^{104)}$ Therefore, any cardiac diseases at the terminal stages can clinically cause heart failure. Although the definition of heart failure seems to be straightforward, its diagnosis is not always easy to make. Many heart failure symptoms are nonspecific or even vague and therefore, of limited diagnostic value. ${ }^{105) 106)}$ Heart failure can be caused by the abnormal function of the myocardium, valves, and/or pericardium and even their combinations, but the exact etiology cannot be clearly differentiated with only history taking and/or physical examination. ${ }^{105) 106)}$ Also, the majority of heart failure patients become symptomatic with the development of myocardial dysfunction, which can be observed with a diverse spectrum of clinical states. Myocardial dysfunction can range from severely decreased ventricular systolic dysfunction with or without ventricular dilation to preserved ventricular systolic function (as assessed by ejection fraction) with normal ventricular size, both of which are $2 \mathrm{im}$ portant types of heart failure, that is heart failure with reduced ejection fraction and heart failure with preserved ejection fraction, respectively. ${ }^{104)}$ Thus, assessment of the systolic as well as the diastolic function of the ventricle plays a central role in the diagnostic process of heart failure. Echocardiography is a well-known and established technique for assessing anatomical structure and function (systolic and diastolic) of the ventricle and this is one of the important reasons why echocardiography has taken a main position in the evaluation of heart failure. In fact, echocardiography has been widely employed to assess changes in ventricular size or volume, shape and function in many clinical trials. ${ }^{107-111)}$ In this respect, there is no doubt that echocardiography is the first-line imaging modality for the evaluation of heart failure patients. Nevertheless, echocardiography suffers from a wide inter-observer variation in measurements of size and function, and furthermore, is vulnerable to image quality that is variable from patient to patient. ${ }^{108)}$ In comparison, the image quality of CMR is not a main concern for analysis, and due to its inherent characteristics, post-processing does not 
require any geometric assumptions for ventricular volume quantification. ${ }^{112)}$ This is of particular importance in the evaluation of heart failure patients, given that many heart failure patients experience geometric changes in their ventricles with a large regional variation in contractility, which can predispose to errors in measurements of volume and ejection fraction by echocardiography. In addition, due to its high accuracy and reproducibility, CMR is believed to be the best reference standard imaging modality for the noninvasive, in vivo assessment of ventricular volume, mass, and function. ${ }^{112-116)}$ CMR also allows for accurate, serial, longitudinal assessment of changes in ventricular size and function after therapeutic interventions on an individual patient basis. Therefore, sample sizes for any study can be far reduced with the use of CMR rather than echocardiography in the longitudinal assessment of ventricular volumes, mass and function. ${ }^{117)}$

Identification of heart failure etiology should be a fundamental question addressed before a final decision is reached on therapeutic plans. Although structure and function are the two main targets for heart failure imaging, CMR can provide clues to underling abnormalities leading to heart failure. ${ }^{118) 119)} \mathrm{CMR}$ is highly accurate and reproducible in ventricular volume and ejection fraction measurements, as commented above. On top of that, myocardial perfusion, viability, and fibrosis imaging (using the LGE technique) by CMR can help identify heart failure etiology and predict prognosis. ${ }^{199) 120)}$ In addition, LV mass quantification by CMR predicts prognosis in heart failure patients. ${ }^{1211122)}$ Among a variety of CMR techniques, LGE CMR provides a non-invasive imaging approach to determine the underlying etiology of heart failure by allowing for a direct interrogation of the myopathic process. ${ }^{118)}$ Differentiation between ischemic and non-ischemic etiology is a basic step for heart failure assessment because this classification exerts a significant effect on patient management decision and patient prognosis. ${ }^{123)}$ LGE CMR can help, in many cases, differentiation of the 2 conditions based on the LGE pattern. Ischemic LGE pattern is characterized by a $100 \%$ involvement of the subendocardium, i.e., subendocardial or transmural, and should be found in a region consistent with a perfusion territory of an epicardial coronary artery. ${ }^{124)}$ In contrast, a non-ischemic LGE pattern usually spares the subendocardium, i.e., mid-wall or epicardial, and/or is inconsistent with a perfusion territory subtended by one coronary artery. ${ }^{124)}$ LGE CMR is also helpful for the diagnosis of any specific type of non-ischemic cardiomyopathy causing heart failure, which can be finally achieved by analyzing the location and pattern of LGE. For example, asymmetric septal hypertrophic cardiomyopathy (HCM) is characterized by LGE of both junctions of the right ventricular (RV) and interventricular septum in the mid-wall, ${ }^{125)}$ whereas apical LGE is frequently found in apical $\mathrm{HCM}^{126)}$ Mid-wall and epicardial LGE in the inferolateral segments can be found in patients with Anderson-Fabry disease, ${ }^{127)}$ whereas LGE found in cardiac sarcoidosis can be variable. But subepicardial or midwall involvement, especially in basal septum, is unique findings of cardiac sarcoidosis. ${ }^{25)}$ Cardiac amyloidosis has a typical LGE pattern, i.e., subendocardial, diffuse ring enhancement, with difficulty in determining optimal inversion time to null normal myocardium due to of its characteristic diffuse myocardial involvement. ${ }^{128)}$ Myocarditis can be diagnosed with LGE CMR and T2 edema imaging. ${ }^{129) 130)}$

Assessment of transmurality of LGE is a good surrogate marker for prognosis prediction. ${ }^{129)}$ Combined CMR assessment of LGE extent and CMR-based LV ejection fraction is reported to be of prognostic value in heart failure patients. ${ }^{131)}$

Approximately $50 \%$ of deaths in heart failure patients occur suddenly and unexpectedly. Thus, prevention of these unexpected events is another important target for heart failure management. Implantable cardioverter-defibrillator (ICD) therapy is a life-saving strategy in heart failure patients with severely decreased LV ejection fraction. Recent studies showed that assessment of myocardial scarring by LGE CMR can improve risk stratification in heart failure patients who are considered potential candidates for ICD therapy. ${ }^{132) 133)} \mathrm{Gao}$ et al. ${ }^{134)}$ also demonstrated that assessment of the total scar by LGE CMR can predict an arrhythmic event. Despite no CMR criteria suggested by the heart failure guideline published in 2012, ${ }^{104)}$ CMR-based ICD therapy seems to hold promise in the prediction of patients who may benefit from ICD therapy. The same strategy can be true for determining potential candidates of cardiac resynchronization therapy (CRT) or for planning CRT procedures, ${ }^{135-137)}$ but this has yet to be confirmed with more data.

Although some case series have reported the safety and effectiveness of the CMR-based approach in heart failure patients with $I C D{ }^{138) 139)}$ this is not generally accepted in the current era, and great care should be exercised before it is adopted into daily clinical practice. Generally, CMR is not recommended in patients with ICD or CRT devices.

\section{Evaluation in patients with risk of heart failure or overt heart failure (general) (protocols may include LV/RV mass and volumes, MR angiography, quantification of valvular disease, and LGE evaluation)}

1. Evaluation of LV function following myocardial infarction $O R$ in heart failure patients (Level of evidence: $A$, Appropriateness criteria: A)

2. Evaluation of LV function following myocardial infarction OR in heart failure patients/patients with technically limited im- 
ages from echocardiogram (Level of evidence: $A$, Appropriateness criteria: A)

3. Quantification of LV function/discordant information that is clinically significant from prior tests (Level of evidence: A, Appropriateness criteria: A)

4. Evaluation in patients with new onset heart failure to assess etiology (Level of evidence: A, Appropriateness criteria: A)

5. Initial evaluation of structure and function for newly suspected or potential heart failure (also including malignancy on current or planned cardiotoxic therapy, survived patients with suspected ventricular dysfunction after chemotherapy, and no prior imaging evaluation/familial or genetic cardiomyopathy in first-degree relative, known congenital heart disease with suspected ventricular dysfunction, acute myocardial infarction during initial hospitalization) (Level of evidence: A, Appropriateness criteria: A)

6. Evaluation to determine patient candidacy of ICD therapy (ejection fraction and/or other structural information) (Level of evidence: A, Appropriateness criteria: A)

7. Initial evaluation to determine patient candidacy of CRT or procedural planning (ejection fraction, fibrosis, scarring, coronary vein variation, and intracavitary thrombus) (Level of evidence: A, Appropriateness criteria: A)

8. Cardiac function follow-up after ICD or CRT (Level of evidence: C, Appropriateness criteria: I)

\section{Clinical scenario 11: patients with congenital heart disease}

Cardiac magnetic resonance is very useful in the evaluation of congenital heart disease because complete contiguous data sets from cardiac base to apex can give complete descriptions of cardiac and extra-cardiac anatomy of both simple and complex congenital heart disease very effectively. Unlike cardiac CT, ionizing radiation exposure is not an issue for CMR, allowing for repeated or sequential evaluation of children and young adults without radiation concern. Nevertheless, CMR is limited in critically-ill patients, especially in acute settings or in patients who cannot cooperate with the medical team, especially neonates and infants. Therefore, CMR is in most cases used as an adjunct approach to echocardiography. Thus, review of echocardiographic images can aid in the appropriate selection of CMR sequences that are likely to give answers to unresolved questions. Although CMR is less operator-dependent when compared to echocardiography, a thorough understanding of the anatomical and functional aspects of any given congenital heart disease is absolutely necessary for a complete interrogation of that particular congenital heart disease patient. A comprehensive evaluation of cardiac and extra-cardiac anatomic structures can be imaged as well, which makes CMR clinically useful in complex congenital heart disease patients.

\section{Anomalies of coronary circulation}

Although CT coronary angiography offers much clearer anatomical information, the origin and proximal course of the coronary arteries can still be relatively well investigated by MR coronary angiography. ${ }^{45)}$ For patients who have difficulty in holding their breath, real-time coronary imaging using diaphragm navigators can be used to minimize image blurring. ${ }^{42)} \mathrm{MR}$ coronary angiography is also useful in the identification of inflammatory changes in the coronary artery, such as changes that would occur with Kawasaki disease. ${ }^{87)}$

Anomalies of great vessels (anomalies of aorta and pulmonary artery)

MR angiography is also very effective for a complete evaluation of the great vessels. Coarctation of the aorta is one representative disease. Transthoracic echocardiography using the 2D and Doppler technique is in many cases enough to diagnose and evaluate hemodynamic severity, but some difficulties can be encountered. Under these situations, CMR can provide diverse and extensive information regarding the severity and extent of stenosis, collateral circulation, and morphologic changes in the ascending aorta, and associated anomalies in the aortic valve. CMR is also a good imaging modality after surgical correction or angioplasty. ${ }^{140-142)}$ Contrastenhanced 3D MR angiography can show abnormal sources of pulmonary blood supply from the major aorta associated with pulmonary stenosis or atresia, though CT angiography is more sensitive at detecting small vessels connected to the pulmonary vessels. ${ }^{143) 144)}$

Due to the ability of CMR to reliably assess the entire aorta and its major branches, aortic disease accompanied by systemic diseases like Marfan syndrome or Ehler-Danlos syndrome can be accurately investigated. In addition, CMR can detect in the preclinical stage abnormal aortic elastic properties in affected patients before aortic dilation clinically manifests. ${ }^{145) 146)}$

\section{Assessment of cardiac chambers and valves}

Cardiac magnetic resonance is an excellent technique for defining the morphologic features of ventricles. ${ }^{147)}$ Thus, it is easy to determine which ventricle the morphological RV is and which ventricle the morphological LV is with comprehensive CMR assessment. For this purpose, detailed knowledge of the LV and RV is a prerequisite; the morphological RV is characterized by multiple coarse trabeculations including the moderator band, and is always connected to the tricuspid valve that is located more apically without exception in relation to the mitral valve. Thus, complex congenital heart disease like transposition of the great arteries or congenitally 
corrected transposition of the great arteries can be accurately assessed. ${ }^{148) 149)}$ In addition, CMR is also very valuable in terms of postoperative follow-up of these patients. ${ }^{149) 150)}$ CMR can easily detect the presence of an intra-cardiac shunt like a ventricular septal defect (VSD) or atrial septal defect (ASD) with jets localization and shunt quantification. ${ }^{151-154)}$

It is in no doubt that echocardiography is the first line of investigation for patients with valve diseases including congenital valve lesions. ${ }^{155)}$ However, CMR can provide additional information to that offered by echocardiography, especially in patients with poor echocardiographic windows and patients with right-sided valve diseases. Thanks to its high spatial resolution and signal-to-noise ratio, morphologic or pathological changes in cardiac valves of interest can be assessed. In addition, phase contrast imaging allows for the accurate quantification of regurgitant volume. This can be specifically applied to patients with significant pulmonary regurgitation. The ability of CMR to quantitate regurgitant volume is particularly valuable for the sequential monitoring of pulmonary regurgitation severity in patients with tetralogy of Fallot who have undergone RV outflow tract patch surgery. ${ }^{156) 157)}$ Sequential evaluation of regurgitant volume along with RV volume changes can help decide the optimal timing of pulmonary valve replacement. ${ }^{158) 159)}$ LGE CMR may contribute to risk stratification, as well. ${ }^{160)}$ However, in patients with a repaired tetralogy of Fallot, other factors should be assessed including tricuspid regurgitation, any residual VSD, branch pulmonary stenosis, aortic regurgitation and LV dysfunction. ${ }^{157)}$ Therefore, a thorough evaluation of the left- and right-sided ventricles and valves with an extension to branch pulmonary arteries and the ascending aorta should be made to manage patients with a repaired tetralogy of Fallot. Another important disease for which CMR can make great contributions to assessment is the Ebstein anomaly and the associated tricuspid regurgitation. ${ }^{161)}$ Obtaining a stack of transaxial cines is recommended, as well as horizontal four-chamber cines for complete visualization of the relationship between the right atrium and $\mathrm{RV}$ in patients with the Ebstein anomaly. A combination of these cine images is necessary for accurate and reproducible volume measurements of the functional RV in these patients, which is not easy to perform using short-axis cines. ${ }^{162)}$ Tricuspid regurgitation is frequently accompanied and the quantification of its severity using phase contrast imaging is also an important integrated part of CMR evaluation in these patients. An ASD or patent foramen ovale is present in up to $50 \%$ of patients and should be sought with an atrial short-axis cine stack, although echocardiography is preferable to CMR for this purpose. Shunt volume can be quantified by phase-contrast imaging.
Postoperative follow-up of congenital heart disease patients

Echocardiography is usually employed for the serial monitoring of congenital heart disease patients after surgery or the trans-catheter technique. In most cases, echocardiography is more than adequate, but in some cases, accurate RV/LV volumes or regurgitant volume quantification is clinically important in deciding the optimal management. CMR can provide more accurate and reproducible ventricular volumes and function measurements than echocardiography. ${ }^{114163)}$ This is especially true for the $R V^{164) 165)}$ which is frequently involved and stressed by the repair of CHD. ${ }^{165)}$ The sequential evaluation of pulmonary regurgitation and its effects on LV and RV functions should be comprehensively evaluated by CMR for effective patient management. ${ }^{166-168)}$ The same strategy can be applied to patients with transposition of the great arteries who have undergone atrial and arterial switch operations, and patients with Fon$\tan$ operations. ${ }^{149) 169-172)}$

In congenital heart disease (protocols may include LV/RV mass and volumes, MR angiography, quantification of valvular disease, and LGE evaluation)

1. Assessment about structure and hemodynamics of congenital heart disease including anomalies of coronary circulation, great vessels, and cardiac chambers and valves (Level of evidence: A, Appropriateness criteria: A)

2. Assessment of post-operative structure and hemodynamics of congenital heart disease including ventricular, great arterial and valvular function and anatomy evaluation (Level of evidence: A, Appropriateness criteria: A)

\section{Clinical scenario 12: patients with valvular heart disease}

Direct visualization of valvular anatomy and the cardiac chambers, and its hemodynamic consequences have been possible since the advent of 2D and Doppler echocardiography. There has been no doubt at all that echocardiography is the standard tool for the initial assessment and longitudinal follow-up of patients with valvular heart disease irrespective of native or prosthetic valves. Therefore, the role of CMR is strictly limited in the field of valvular heart disease in daily clinical practice. However, over the last 20 years, CMR has made remarkable improvements in its image quality, scan time, and even hemodynamic assessment and, as a result, it has emerged as an alternative noninvasive imaging modality that is without ionizing radiation exposure in patients with valvular diseases. Thanks to its excellent signal-to-noise ratio and good spatial resolution, CMR can provide beautiful images of the valve anatomy and can thus also provide valuable insight into the mechanisms of 
valvular lesions. Regurgitant or stenotic flow jets are well visualized on cine imaging without any contrast agent. However, jet size or density should not be used for qualitative evaluation of the severity of valvular disease. The visibility extent of any jet observed in cine CMR imaging does depend on the CMR setting of specific sequences. While CMR can quantify the severity of stenotic or regurgitant valve lesions via the phase contrast imaging technique, velocities can be underestimated if the scan slice is not optimally aligned to regurgitant or stenotic jets. In the evaluation of patients with valvular disease, the advantage of CMR is in its power to reveal consequences of the valvular lesion, including the effects on LV or RV volumes, systolic function and left atrial or right atrial volumes. More fascinating is the fact that all of these examinations can be performed without administration of contrast agents, and thus can be conducted in patients with renal failure without fear of nephrogenic systemic fibrosis. The SSFP cine pulse sequence is the most widely used CMR technique for investigating valve anatomy and motion. This pulse sequence is well known to have excellent bloodto-myocardium contrast and a high intrinsic signal-to-noise ratio. ${ }^{173)}$ With this technique, CMR can create tomographic images at any plane and at any level. Phase contrast imaging is used for velocity measurements and can be considered in patients whose echocardiographic images are inconclusive or inadequate for reliable evaluation. However, because temporal resolution of phase contrast imaging is much lower than Doppler echocardiography, we should consider a chance that the peak velocity will be underestimated.

One thing that should be kept in mind is that almost all CMR validation studies in relation to valvular heart disease were performed with echocardiography as the gold standard and only in a small number of patients. ${ }^{174-180)}$ Nevertheless, the peak antegrade velocity, pressure gradient, and stenotic valve area can be accurately calculated with CMR in patients with valve stenosis. In addition, the regurgitant valve area, regurgitant volume and regurgitant fraction can be assessed in patients with valvular regurgitation. Like Doppler echocardiography, however, a misalignment of more than 20 degrees between the phase direction and the blood flow direction makes velocity measurements with CMR inaccurate. ${ }^{180)}$ Reproducibility of LV and RV volume quantification is one of the most important strengths of CMR. Any significant valvular regurgitation can cause LV or RV volume overload and can finally precipitate the LV or RV to remodel and change geometry. LV and RV volumes can be accurately measured with CMR without any assumption of ventricular geometry. This is especially useful for right-sided valve regurgitation, because echocardiography cannot accurately assess RV volume and ejection fraction due to its complex geometry and shape. In particular, pulmonary regurgitation, a major late complication after surgical correction of tetralogy of Fallot, has been frequently assessed using CMR-based RV volume measurements ${ }^{156) 164) 181) 182)}$ and now CMR is generally accepted as the gold standard method for in vivo RV assessment. ${ }^{183) 184)}$ Also, although CMR is safe in patients with prosthetic valves at $1.5-\mathrm{T}$, the metal contained within prosthetic valves generates artifacts and signal loss, and thus CMR validation in patients with prosthetic valves is very limited. ${ }^{185-187)}$ Thus, as of now, the clinical use of CMR in valvular heart disease is limited. In this respect, the use of CMR in valve diseases is currently recommended only for patients with technically challenging echocardiographic images.

In valvular heart disease (protocols may include $L V / R V$ mass and volumes, MR angiography, quantification of valvular disease, and LGE evaluation)

1. Characterization of native and prosthetic cardiac valves-including planimetry of stenotic disease and quantification of regurgitant disease/patients with technically limited images from transthoracic or transesophageal echocardiography (Level of evidence: A, Appropriateness criteria: A)

\section{Clinical scenario 13: patients with suspected or diagnosed myocardial disease}

Myocardial diseases are one of the most important disease entities in the field of cardiology. They are usually classified into 2 categories, namely cardiomyopathy and myocarditis.

\section{Cardiomyopathy}

Cardiomyopathy is classified into 5 different categories, although there are definitely situations in which the suggested classification system cannot fully address some of the myopathic phenotypes. Unlike HCM and dilated cardiomyopathy (DCM), arrhythmogenic right ventricular dysplasia/cardiomyopathy (ARVD/C) is diagnosed on a histologic basis and characterized by progressive fibrofatty replacement in the $R V$, resulting in morphological and functional changes of the RV. ARVD/C can sometimes involve the LV and clinically manifests as a DCM phenotype, but this is not always true.

Recently, the role of CMR has been significantly increased in the diagnosis of ARVD/C. Generally, the diagnosis of ARVD/C depends on the demonstration of structural, functional, ECG abnormalities, and their combinations. According to the original task force criteria, RV morphological and functional abnormalities were predominantly estimated by echocardiography. However, though useful, echocardiography is not the best approach for assessing morphological and functional changes in the RV. CMR is the gold standard for this purpose and thus, the revised task force criteria encompassed the CMR- 
derived definition of RV morphological and functional abnormalities including RV regional wall motion abnormalities, correct quantification of RV volumes, aneurysm/trabecular disarray, and increased myocardial signal suggestive of fatty replacement. ${ }^{188)}$ However, the role of LGE CMR has not been mentioned in this new proposed criteria. ${ }^{188)} \mathrm{CMR}$ can allow for early detection of patients with genotype (+), but with phenotype (-). ${ }^{189)}$ In addition to its diagnostic role, CMR including LGE imaging can play a prognostic role in ARVD/ C patients. ${ }^{190) 191)}$ However, given that the normal variants of the RV are usually greater than those found in the LV, great caution should be exercised in the interpretation of RV findings found in CMR.

As described in the heart failure section, CMR can be very helpful in the differential diagnosis or evaluation of specific cardiomyopathies, especially thanks to the advent of LGE imaging. Aside from ischemia-induced myocardial disease, the LGE pattern of non-ischemic cardiomyopathies usually spares the subendocardium, i.e., midwall or epicardial, and/or is inconsistent with a perfusion territory subtended by one coronary artery. ${ }^{124)}$ The LGE pattern depends on the type of cardiomyopathy, though it is not always or totally differential. ${ }^{124)}$ For example, it has been reported that cardiac amyloidosis has a typical LGE pattern, i.e., subendocardial, diffuse ring enhancement, with difficulty in determining optimal inversion time to null normal myocardium due to its characteristic diffuse involvement, ${ }^{128) 192)}$ although the precise pattern of LGE in cardiac amyloidosis has been reported to be more variable in recent studies than what was previously believed. ${ }^{193) 194)}$ However, LGE CMR is expected to facilitate the easy detection of cardiac involvement in patients with sarcoidosis, and to be used in monitoring treatment responses because the degree of LGE is reduced with successful treatment of steroid therapy, suggesting the possibility that it may be used as a therapeutic surrogate marker. ${ }^{195)}$ Trastuzumab-induced cardiomyopathy is characterized by LGE of the lateral wall of the LV within the mid myocardial portion, ${ }^{196)}$ but this finding requires further data. LV noncompaction cardiomyopathy has been increasingly recognized along with the revolutionary evolution of cardiac imaging techniques. LV noncompaction cardiomyopathy is characterized by 2 factors; prominent LV trabeculae and deep inter-trabecular recesses. ${ }^{197)}$ Since this cardiomyopathy can be diagnosed by LV morphologic features, the role of CMR has been increasingly important with its unprecedented high signal-to-noise ratio. A ratio of noncompacted/compacted myocardium of more than 2.3 in diastole was suggested for the CMR diagnosis of this disease entity. ${ }^{198)}$ CMR also precisely interrogates the transition zone between affected and non-affected LV segments due to its good spatial resolution. Stressinduced cardiomyopathy was recently incorporated into cardiomyopathy classification, which is usually characterized by transient regional LV systolic dysfunction in the absence of obstructive epi- cardial coronary disease on coronary angiography. In most cases, the LV apex is involved, but sometimes the mid-ventricle or basal ventricle alone can be affected. Although echocardiography is usually enough for the diagnosis of stress-induced cardiomyopathy, CMR seems to be a promising imaging modality for confirming regional wall motion abnormality and for differentiating this (no LGE is present in most cases) from acute myocardial infarction or myocarditis (LGE is frequently present) based on the presence or absence of LGE. ${ }^{199-201)}$

\section{Myocarditis}

Myocarditis is another important myocardial disease of which a diagnosis is not easy to make. The gold standard method of diagnosis is histologic confirmation of myocardial inflammation, which is sometimes difficult and limited by the patchy involvement of the inflammatory process. Myocardial biopsy carries some risk, as well. The unique ability of CMR to visualize myocardial tissue changes is the reason for CMR being increasingly employed in the diagnostic process of myocarditis. ${ }^{2022203)}$ Anticipated tissue pathological changes in acute myocarditis include intracellular/interstitial edema, hyperemia, capillary leakage, and cellular necrosis with fibrosis, all of which can be easily found with a variety of CMR techniques like T2 edema imaging and LGE or the early enhancement technique. CMR can show increases in myocardial signals on T2-weighted and LGE images in acute myocarditis. ${ }^{129) 130)}$ For the accurate diagnosis of cardiomyopathy etiology, the role of CMR is increasingly recognized and emphasized. There is no doubt that the gold standard method for etiological diagnosis is histological confirmation and the firstline imaging modality in patients under suspicion for myocardial disease is echocardiography. However, a comprehensive CMR protocol including cine, LGE, and sometimes perfusion techniques can provide etiological diagnosis and prognostic implications.

\section{In suspected or diagnosed myocardial disease (protocols may include LV/RV mass and volumes, MR angiography, quantification of valvular disease, and LGE evaluation)}

1. Evaluation for ARVD/C patients presenting with syncope or ventricular arrhythmia (Level of evidence: $A$, Appropriateness criteria: A)

2. Evaluation of myocarditis or myocardial infarction with normal coronary arteries/positive cardiac enzymes without obstructive atherosclerosis on angiography (Level of evidence: A, Appropriateness criteria: A)

3. Evaluation of specific cardiomyopathies \{infiltrative (amyloid, sarcoid, etc.) or due to cardiotoxic therapies $\}$ (Level of evidence: A, Appropriateness criteria: A) 


\section{Clinical scenario 14: evaluation in patients with hypertrophic cardiomyopathy}

Hypertrophic cardiomyopathy is the most common genetic cardiovascular disorder that is characterized by sarcomere gene mutation. ${ }^{204)}$ Accurate diagnosis of HCM is crucial because HCM patients must alter their life-style to prevent unexpected dismal events. Family screening should be done, as well. Transthoracic echocardiography is the most commonly used imaging modality for the diagnosis of HCM by identification of LV hypertrophy and systolic anterior motion of the mitral valve with associated LV outflow tract dynamic obstruction. CMR, thanks to its high signal-to-noise ratio and good spatial resolution, has established its role in the diagnosis of HCM, because phenotypic expressions of HCM are diverse and complex, and thus transthoracic echocardiography sometimes misses the hypertrophic segments, especially in the apex, posteroseptum and lateral free wall, difficult areas to evaluate with transthoracic echocardiography due to its low lateral spatial resolution. ${ }^{205-208)}$ The LV apex is notably much more difficult to evaluate with echocardiography due in part to its proximity to the echocardiographic probe. Thus, diagnosis of apical HCM may be underreported using transthoracic echocardiography. ${ }^{207)}$ In addition, the detection of apical aneurysm is problematic with transthoracic echocardiography. However, a more sensitive discovery of apical aneurysm in HCM is clinically relevant, given that its prevalence is not low and that its presence is associated with cardiovascular morbidity and mortality. ${ }^{209 / 210)}$ In this respect, cine CMR can provide more accurate information about the LV hypertrophic pattern and the presence or absence of apical aneurysm in HCM patients whose echocardiographic images are technically suboptimal and nondiagnostic. The phenotypic heterogeneity of HCM sometimes involves morphologic abnormalities of the RV, which can be assessed with cine CMR more accurately than with transthoracic echocardiography, although the clinical or prognostic significance of RV involvement in $\mathrm{HCM}$ is yet to be determined. ${ }^{211)}$

Late gadolinium enhancement CMR can provide a unique opportunity for patients with unexplained LV hypertrophy. ${ }^{212)}$ LGE in $\mathrm{HCM}$ is predominantly located at the anterior and posterior insertion points of the RV into the septum with a typical non-subendocardial pattern. ${ }^{212)}$ However, LGE can be found in different locations, not confined to hypertrophic segments. ${ }^{126)}$ Myocardial fibrosis is generally accepted as the main pathohistological feature of HCM, which can be accurately assessed with LGE CMR. ${ }^{213-215)}$ CMR-determined myocardial fibrosis has been repeatedly reported to be closely associated with a grave prognosis in HCM patients and has advantages over traditional risk factors for future sudden death. ${ }^{209 / 216-221)}$ Also, the extent of LGE is reported to be linked to progressive ventricular remodeling. ${ }^{222)}$ Given the strong association between the presence of LGE and ventricular tachyarrhythmia on Holter monitoring ${ }_{1}^{209(220) 223)}$ it is conceivable that LGE in HCM can be a potential arbitrator of ventricular tachyarrhythmia. Although LGE CMR looks promising, there still seems to be insufficient data for inserting ICDs in HCM patients based only on LGE CMR findings, given the technical and methodological issues of LGE assessment. ${ }^{224)}$

Hypertrophic cardiomyopathy is a genetic disease with an autosomal dominant trait, and thus first-degree relatives have a 50\% chance of being gene carriers. Although genotyping is the best way to detect possible future clinical manifestations of HCM, it is limited by high cost and the variable penetrance of the disease. Another problem is that approximately $40 \%$ of HCM patients are genetically negative. Therefore, the most realistic screening modalities that can be applied clinically are the ECG and echocardiogram. However, some CMR findings have recently been found to suggest early imaging manifestations of HCM including myocardial crypts, ${ }^{225(226)}$ elongated mitral valve leaflets, ${ }^{227}$ and the presence of LGE suggesting $\mathrm{HCM}^{\left.2{ }^{228}\right)}$ All of these findings should be confirmed in future CMR studies, but if combined with genetic testing, these CMR evaluations have the potential to identify HCM at an early stage of the disease. Current and emerging recommendations of CMR are summarized in the following table.

\section{Evaluation in HCM}

1. In HCM patients with inconclusive or inadequate echocardiography (Level of evidence: A, Appropriateness criteria: A)

2. To define apical hypertrophy and/or aneurysm if echocardiography is inconclusive (Level of evidence: A, Appropriateness criteria: A)

3. In selected patients with known HCM, when sudden cardiac death risk stratification is inconclusive after documentation of the conventional risk factors/use of LGE evaluation (Level of evidence: A, Appropriateness criteria: A)

\section{Miscellaneous disease}

\section{Clinical scenario 15: evaluation of cardiac mass (suspected tumor} or thrombus)/use of contrast for perfusion and enhancement

Intracardiac mass is not uncommonly seen in clinical situations with the thrombus being the most common intracardiac mass. Notably, a left atrial thrombus in patients with atrial fibrillation and a LV thrombus in patients with severe LV systolic dysfunction due to myocardial infarction or underlying cardiomyopathy are frequently discovered. Several previous studies show that the detection rate of an intracardiac thrombus especially the LV thrombus using LGE 


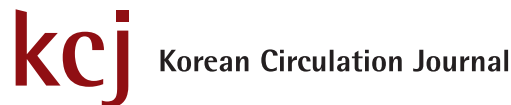

imaging with varying degrees of inversion time is better than that of conventional echocardiography or contrast echocardiography. ${ }^{229-231)}$ The intramural type of LV thrombus is especially best detected by contrast CMR. ${ }^{232)}$ Regarding intracardiac tumors, the most important information provided by CMR is extent of tumor and its relationship with adjacent structures. Although malignant tumors are rare, tissue characterization of a tumor would reveal the nature of the tumor. Myxoma is the most common intracardiac tumor and CMR findings of cardiac myxoma show increased signal intensity in T2-weighted images but the signal composition is usually heterogeneous. The differential diagnosis of a high signal intensity lesion on T1-weighted images includes lipoma, tumor with recent hemorrhage, and melanoma (due to the effects of melanin). For the accurate differentiation in this situation, fat saturation technique provides additional information. A lesion with low signal intensity on T1-weighted images may represent a cyst, a signal void in a vascular malformation, a calcified lesion or the presence of air. As water content typically shows high signal intensity on T2-weighted images, intracardiac or pericardial cyst provides high signal intensity. In addition, myxoma, lipoma or metastatic tumor can also be shown to have high signal intensity on T2-weighted images. So, for further differentiation, perfusion imaging, early and late gadolinium enhancement imagings are usually needed. In the early phase, after injection at 1-2 minutes, necrotic areas in malignant tumors show up as dark areas surrounded by enhancement elsewhere. In the later phase, malignant tumors typically show contrast enhancement indicating tissue vascularity. Such enhancement pattern is usually absent in cystic lesions and most benign tumors except for myxomas. $^{233)}$ For the differentiation from myxoma, its location and presence of stalk would provide important information. Adjacent tissue infiltration is best estimated by CMR using first pass perfusion imaging and the LGE technique. ${ }^{233-235)}$

Evaluation of cardiac mass (suspected tumor or thrombus)/ use of contrast for perfusion and enhancement (Level of evidence: A, Appropriateness criteria: A)

\section{Clinical scenario 16: evaluation of pericardium}

Cardiac magnetic resonance can provide information about the accurate amount of pericardial effusion and pericardial thickness. ${ }^{236) 237)}$ Using LGE with fat saturation techniques, the degree of pericardial inflammation can be assumed in patients with constrictive pericarditis. Therefore it can predict the effectiveness of intensive anti-inflammatory medications before a pericardiectomy. ${ }^{238)}$ Pericardial tumors are also detected and their tissue characterization is also possible with good reliability. The absence of the pericardium can be suspected by a leftward shift of the long axis LV. Any protrusion of any portion of the heart can suggest pericardial absence. ${ }^{239}$

Evaluation of pericardium (pericardial mass, constrictive pericarditis) (Level of evidence: B, Appropriateness criteria: A)

\section{Clinical scenario 17: evaluation for aortic dissection}

MR angiography has been accepted as a good modality for detecting a dissection flap and entry tear site. Transesophageal echocardiography or CT scans are widely used modalities. However the aortic arch is a weak point with transesophageal echocardiography and CT scans need iodine contrast agents and radiation. A previous study shows that cardiac CT or CMR have advantages over transthoracic echocardiography. In a meta-analysis of 1139 patients, the pooled sensitivity (98-100\%) and specificity (95-98\%) were comparable between these imaging techniques. The pooled positive likelihood ratio appeared to be higher for CMR \{positive likelihood ratio, 25.3; 95\% Cl (11.1-57.1)\} than for transesophageal echocardiography $(14.1 ; 6.0-33.2)$ or helical CT (13.9; 4.2-46.0). ${ }^{240)}$

Evaluation for aortic dissection (Level of evidence: A, Appropriateness criteria: A)

\section{Clinical scenario 18: evaluation of pulmonary veins prior} to radiofrequency ablation for atrial fibrillation/left atrial and pulmonary venous anatomy including dimensions of veins for mapping purposes

An accurate anatomic view of the left atrium and pulmonary veins is essential before radiofrequency ablation of pulmonary veins in patients with atrial fibrillation. Currently cardiac CT provides excellent images to guide catheter-based pulmonic vein isolation, and CMR can also provide excellent imaging views about anatomical variants of the pulmonic vein. ${ }^{241-243)}$ Some studies have reported that diverse variations of the pulmonic vein exist and these have been well correlated with cardiac CT and CMR. ${ }^{241)}$

Evaluation of pulmonary veins prior to radiofrequency ablation for atrial fibrillation/left atrial and pulmonary venous anatomy including dimensions of veins for mapping purposes (Level of evidence: B, Appropriateness criteria: A) 
Clinical scenario 19: anatomic assessment before percutaneous device closure of atrial septal defect or ventricular septal defect/ anatomic assessment before percutaneous aortic valve replacement

The accurate measurement of ASD shape and size is essential in the selection of an appropriate device. Accurate classification of the ASD type, non-invasive measurement of Qp/Os (pulmonary flow/ systemic flow ratio), and detection of concomitant congenital anomaly are extremely important and can be reliably done by CMR. Several studies have shown that CMR based ASD correlated well to transesophageal echocardiography based on defects size. En face CMR with an optimized imaging plane can determine ASD flow, size, and morphology. ${ }^{244245)}$ Thomson et al. ${ }^{246)}$ reported that CMR provided information incremental to comprehensive standard evaluation that altered clinical management in 20\% of patients. Recently, the catheter-based percutaneous aortic valve replacement has been introduced and the number of this procedure being performed has increased markedly. While transesophageal echocardiography and cardiac CT are known to provide excellent anatomical and functional images of the left ventricular outflow tract, the relationship to the coronary ostium, and the severity of calcification, CMR has been reported to provide good information albeit with a tendency to have larger values than transthoracic echocardiography for all measurements. ${ }^{247}$

Anatomic assessment before percutaneous device closure of ASD or VSD/anatomic assessment before percutaneous aortic valve replacement (Level of evidence: B, Appropriateness criteria: A)

\section{Acknowledgments}

This work was supported by the Guideline Development Fund of the Korean Society of Cardiology, the Korean Society of Radiology, and Korean Society of Cardiovascular Imaging.

Rating Panel: Dae-Hee Kim, Kye Hun Kim, Sung-A Chang, SeongMi Park, Hyuk-Jae Chang, Wook Jin Chung, Hae-Ok Jung, Sang-Chol Lee, Jong-Won Ha, Jun Kwan, Eun Joo Kang, Joon-Won Kang, Sung Min Ko, Hyon Joo Kwag, Yon Mi Sung, Whal Lee, Ki-Seuk Choo, Sang II Choi, Jung Im Jung, Heon Lee

Consultation Panel: Euisoo Shin, Ein-Soon Shin

Review Panel: Seung-Pyo Lee, II-Suk Sohn, Ho-Joong Yoon, Jae Seung Seo, Jong-Min Lee, Byoung Wook Choi, Chung II Noh, Lucy Young Min Eun, Gi Beom Kim, Ein-Soon Shin

Steering Committee: Yong-Jin Kim, Sang-Chol Lee, Tae Hoon Kim,
Yeon Hyeon Choe, Dae-Won Sohn

\section{Supplementary Materials}

The online-only Data Supplement is available with this article at http://dx.doi.org/10.4070/kcj.2014.44.6.359.

\section{References}

1. Beanlands RS, Chow BJ, Dick A, et al. CCS/CAR/CANM/CNCS/CanSCMR joint position statement on advanced noninvasive cardiac imaging using positron emission tomography, magnetic resonance imaging and multidetector computed tomographic angiography in the diagnosis and evaluation of ischemic heart disease--executive summary. Can J Cardiol 2007;23:107-19.

2. Pennell DJ, Sechtem UP, Higgins $C B$, et al. Clinical indications for cardiovascular magnetic resonance (CMR): Consensus Panel report. Eur Heart J 2004;25:1940-65.

3. Pennell DJ, Sechtem UP, Higgins CB, et al. Clinical indications for cardiovascular magnetic resonance (CMR): Consensus Panel report. J Cardiovasc Magn Reson 2004;6:727-65.

4. ASCI CCT and CMR Guideline Working Group, Kitagawa K, Choi BW et al. ASCl 2010 appropriateness criteria for cardiac magnetic resonance imaging: a report of the Asian Society of Cardiovascular Imaging cardiac computed tomography and cardiac magnetic resonance imaging guideline working group. Int J Cardiovasc Imaging 2010;26 Suppl 2:173-86.

5. Hendel RC, Patel MR, Kramer CM, et al. ACCF/ACR/SCCT/SCMR/ASNC/ NASCI/SCAI/SIR 2006 appropriateness criteria for cardiac computed tomography and cardiac magnetic resonance imaging: a report of the American College of Cardiology Foundation Quality Strategic Directions Committee Appropriateness Criteria Working Group, American College of Radiology, Society of Cardio-vascular Computed Tomography, Society for Cardiovascular Magnetic Resonance, American Society of Nuclear Cardiology, North American Society for Cardiac Imaging, Society for Cardiovascular Angiography and Interventions, and Society of Interventional Radiology. J Am Coll Cardiol 2006;48:1475-97.

6. Gersh BJ, Maron BJ, Bonow RO, et al. 2011 ACCF/AHA guideline for the diagnosis and treatment of hypertrophic cardiomyopathy: executive summary: a report of the American College of Cardiology Foundation/American Heart Association Task Force on Practice Guidelines. Circulation 2011;124:2761-96.

7. Patel MR, White RD, Abbara S, et al. 2013 ACCF/ACR/ASE/ASNC/SCCT/ SCMR appropriate utilization of cardiovascular imaging in heart failure: a joint report of the American College of Radiology Appropriateness Criteria Committee and the American College of Cardiology Foundation Appropriate Use Criteria Task Force. J Am Coll Cardiol 2013; 61:2207-31.

8. Taylor AJ, Cerqueira M, Hodgson JM, et al. ACCF/SCCT/ACR/AHA/ASE/ ASNC/NASCI/SCAI/SCMR 2010 appropriate use criteria for cardiac computed tomography. A report of the American College of Cardiology Foundation Appropriate Use Criteria Task Force, the Society of Cardiovascular Computed Tomography, the American College of Radi- 
ology, the American Heart Association, the American Society of Echocardiography, the American Society of Nuclear Cardiology, the North American Society for Cardiovascular Imaging, the Society for Cardiovascular Angiography and Interventions, and the Society for Cardiovascular Magnetic Resonance. J Am Coll Cardio/ 2010;56:1864-94.

9. Wilke $N$, Jerosch-Herold $M$, Wang $Y$, et al. Myocardial perfusion reserve: assessment with multisection, quantitative, first-pass MR imaging. Radiology 1997;204:373-84.

10. Schwitter J, Nanz D, Kneifel S, et al. Assessment of myocardial perfusion in coronary artery disease by magnetic resonance: a comparison with positron emission tomography and coronary angiography. Circulation 2001;103:2230-5.

11. Giang TH, Nanz D, Coulden $R$, et al. Detection of coronary artery disease by magnetic resonance myocardial perfusion imaging with various contrast medium doses: first European multi-centre experience. Eur Heart J 2004;25:1657-65.

12. Pilz G, Bernhardt $P$, Klos M, Ali E, Wild M, Höfling B. Clinical implication of adenosine-stress cardiac magnetic resonance imaging as potential gatekeeper prior to invasive examination in patients with $\mathrm{AHA} /$ ACC class II indication for coronary angiography. Clin Res Cardiol 2006;95:531-8.

13. Greenwood JP, Maredia N, Younger JF, et al. Cardiovascular magnetic resonance and single-photon emission computed tomography for diagnosis of coronary heart disease (CE-MARC): a prospective trial. Lancet 2012;379:453-60.

14. Schwitter J, Wacker CM, van Rossum AC, et al. MR-IMPACT: comparison of perfusion-cardiac magnetic resonance with single-photon emission computed tomography for the detection of coronary artery disease in a multicentre, multivendor, randomized trial. Eur Heart $J$ 2008;29:480-9.

15. Schwitter J, Wacker CM, Wilke N, et al. MR-IMPACT II: Magnetic Resonance Imaging for Myocardial Perfusion Assessment in Coronary artery disease Trial: perfusion-cardiac magnetic resonance vs. singlephoton emission computed tomography for the detection of coronary artery disease: a comparative multicentre, multivendor trial. Eur Heart J 2013;34:775-81.

16. Nandalur KR, Dwamena BA, Choudhri AF, Nandalur MR, Carlos RC. Diagnostic performance of stress cardiac magnetic resonance imaging in the detection of coronary artery disease: a meta-analysis. J Am Coll Cardiol 2007;50:1343-1353.

17. Schwitter J, Wacker CM, Wilke N, et al. Superior diagnostic performance of perfusion-cardiovascular magnetic resonance versus SPECT to detect coronary artery disease: the secondary endpoints of the multicenter multivendor MR-IMPACT II (Magnetic Resonance Imaging for Myocardial Perfusion Assessment in Coronary Artery Disease Trial). J Cardiovasc Magn Reson 2012;14:61.

18. Paetsch I, Jahnke C, Ferrari VA, et al. Determination of interobserver variability for identifying inducible left ventricular wall motion abnormalities during dobutamine stress magnetic resonance imaging. Eur Heart J 2006;27:1459-64.

19. Hundley WG, Hamilton CA, Thomas MS, et al. Utility of fast cine magnetic resonance imaging and display for the detection of myocardial ischemia in patients not well suited for second harmonic stress echo- cardiography. Circulation 1999;100:1697-702.

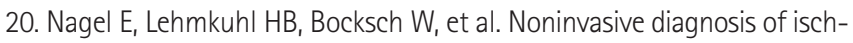
emia-induced wall motion abnormalities with the use of high-dose dobutamine stress MRI: comparison with dobutamine stress echocardiography. Circulation 1999;99:763-70.

21. Paetsch I, Jahnke $C$, Wahl $A$, et al. Comparison of dobutamine stress magnetic resonance, adenosine stress magnetic resonance, and adenosine stress magnetic resonance perfusion. Circulation 2004;110: 835-42.

22. Pennell DJ, Underwood SR, Manzara CC, et al. Magnetic resonance imaging during dobutamine stress in coronary artery disease. Am J Cardiol 1992;70:34-40.

23. Rerkpattanapipat P, Gandhi SK, Darty SN, et al. Feasibility to detect severe coronary artery stenoses with upright treadmill exercise magnetic resonance imaging. Am J Cardio/ 2003;92:603-6.

24. Schalla $S$, Klein $C$, Paetsch I, et al. Real-time MR image acquisition during high-dose dobutamine hydrochloride stress for detecting left ventricular wall-motion abnormalities in patients with coronary arterial disease. Radiology 2002;224:845-51.

25. Patel MR, Cawley PJ, Heitner JF, et al. Detection of myocardial damage in patients with sarcoidosis. Circulation 2009;120:1969-77.

26. Wahl A, Paetsch I, Gollesch A, et al. Safety and feasibility of high-dose dobutamine-atropine stress cardiovascular magnetic resonance for diagnosis of myocardial ischaemia: experience in 1000 consecutive cases. Eur Heart J 2004;25:1230-6.

27. Kuijpers D, Ho KY, van Dijkman PR, Vliegenthart R, Oudkerk M. Dobutamine cardiovascular magnetic resonance for the detection of myocardial ischemia with the use of myocardial tagging. Circulation 2003; 107:1592-7.

28. Korosoglou G, Lehrke S, Wochele A, et al. Strain-encoded CMR for the detection of inducible ischemia during intermediate stress. JACC Cardiovasc Imaging 2010;3:361-71.

29. Kim WY, Danias PG, Stuber M, et al. Coronary magnetic resonance angiography for the detection of coronary stenoses. N Engl J Med 2001; 345:1863-9.

30. Sakuma H, Ichikawa Y, Chino S, Hirano T, Makino K, Takeda K. Detection of coronary artery stenosis with whole-heart coronary magnetic resonance angiography. J Am Coll Cardiol 2006;48:1946-50.

31. Kato $S$, Kitagawa K, Ishida $N$, et al. Assessment of coronary artery disease using magnetic resonance coronary angiography: a national multicenter trial. J Am Coll Cardio/ 2010;56:983-91.

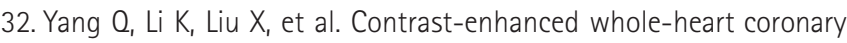
magnetic resonance angiography at 3.0-T: a comparative study with X-ray angiography in a single center. J Am Coll Cardio/ 2009;54:69-76.

33. Hamdan A, Asbach $P$, Wellnhofer $E$, et al. A prospective study for comparison of $\mathrm{MR}$ and $\mathrm{CT}$ imaging for detection of coronary artery stenosis. JACC Cardiovasc Imaging 2011;4:50-61.

34. Schuetz GM, Zacharopoulou NM, Schlattmann P, Dewey M. Metaanalysis: noninvasive coronary angiography using computed tomography versus magnetic resonance imaging. Ann Intern Med 2010;152: 167-77.

35. Nagata M, Kato $S$, Kitagawa $K$, et al. Diagnostic accuracy of 1.5-T unenhanced whole-heart coronary MR angiography performed with 
32-channel cardiac coils: initial single-center experience. Radiology 2011;259:384-92.

36. Hundley WG, Morgan TM, Neagle CM, Hamilton CA, Rerkpattanapipat $P_{1}$ Link KM. Magnetic resonance imaging determination of cardiac prognosis. Circulation 2002;106:2328-33.

37. Jahnke $C_{1}$ Nagel $E_{1}$ Gebker $R_{1}$ et al. Prognostic value of cardiac magnetic resonance stress tests: adenosine stress perfusion and dobutamine stress wall motion imaging. Circulation 2007;115:1769-76.

38. Gargiulo P, Dellegrottaglie S, Bruzzese $D$, et al. The prognostic value of normal stress cardiac magnetic resonance in patients with known or suspected coronary artery disease: a meta-analysis. Circ Cardiovasc Imaging 2013;6:574-82.

39. Lipinski MJ, McVey CM, Berger JS, Kramer CM, Salerno M. Prognostic value of stress cardiac magnetic resonance imaging in patients with known or suspected coronary artery disease: a systematic review and meta-analysis. J Am Coll Cardiol 2013;62:826-38.

40. Yoon YE, Kitagawa $K$, Kato $S$, et al. Prognostic value of coronary magnetic resonance angiography for prediction of cardiac events in patients with suspected coronary artery disease. J Am Coll Cardiol 2012; 60:2316-22

41. Cheitlin MD, De Castro CM, McAllister HA. Sudden death as a complication of anomalous left coronary origin from the anterior sinus of Valsalva, A not-so-minor congenital anomaly. Circulation 1974;50: 780-7.

42. Bunce $\mathrm{NH}$, Lorenz $\mathrm{CH}$, Keegan J, et al. Coronary artery anomalies: assessment with free-breathing three-dimensional coronary MR angiography. Radiology 2003;227:201-8.

43. Gharib AM, Ho VB, Rosing DR, et al. Coronary artery anomalies and variants: technical feasibility of assessment with coronary MR angiography at 3 T. Radiology 2008;247:220-7.

44. McConnell MV, Ganz P, Selwyn AP, Li W, Edelman RR, Manning WJ. Identification of anomalous coronary arteries and their anatomic course by magnetic resonance coronary angiography. Circulation 1995; 92:3158-62.

45. Taylor $A M$, Thorne $S A$, Rubens $M B$, et al. Coronary artery imaging in grown up congenital heart disease: complementary role of magnetic resonance and x-ray coronary angiography. Circulation 2000;101: 1670-8.

46. Casolo G, Del Meglio J, Rega L, et al. Detection and assessment of coronary artery anomalies by three-dimensional magnetic resonance coronary angiography. Int J Cardiol 2005;103:317-22.

47. Clemente $A$, Del Borrello $M$, Greco $P$, et al. Anomalous origin of the coronary arteries in children: diagnostic role of three-dimensional coronary MR angiography. Clin Imaging 2010;34:337-43.

48. Plein S, Greenwood JP, Ridgway JP, Cranny G, Ball SG, Sivananthan MU. Assessment of non-ST-segment elevation acute coronary syndromes with cardiac magnetic resonance imaging. J Am Coll Cardiol 2004:44:2173-81.

49. Kwong RY, Schussheim AE, Rekhraj S, et al. Detecting acute coronary syndrome in the emergency department with cardiac magnetic resonance imaging. Circulation 2003;107:531-7.

50. Cury RC, Shash K, Nagurney JT, et al. Cardiac magnetic resonance with T2-weighted imaging improves detection of patients with acute coronary syndrome in the emergency department. Circulation 2008; 118:837-44.

51. Miller $C D$, Hwang $W$, Case $D$, et al. Stress CMR imaging observation unit in the emergency department reduces 1-year medical care costs in patients with acute chest pain: a randomized study for comparison with inpatient care. JACC Cardiovasc Imaging 2011;4:862-70.

52. Miller CD, Case LD, Little WC, et al. Stress CMR reduces revascularization, hospital readmission, and recurrent cardiac testing in intermediate-risk patients with acute chest pain. JACC Cardiovasc Imaging 2013;6:785-94

53. Kern MJ, Lerman A, Bech JW, et al. Physiological assessment of coronary artery disease in the cardiac catheterization laboratory: a scientific statement from the American Heart Association Committee on Diagnostic and Interventional Cardiac Catheterization, Council on Clinical Cardiology. Circulation 2006;114:1321-41.

54. Smith SC Jr, Feldman TE, Hirshfeld JW Jr, et al. ACC/AHA/SCAI 2005 guideline update for percutaneous coronary intervention: a report of the American College of Cardiology/American Heart Association Task Force on Practice Guidelines (ACC/AHA/SCAI Writing Committee to Update 2001 Guidelines for Percutaneous Coronary Intervention). Circulation 2006;113:e166-286.

55. Smith SC Jr, Feldman TE, Hirshfeld JW Jr, et al. ACC/AHA/SCAI 2005 guideline update for percutaneous coronary intervention: a report of the American College of Cardiology/American Heart Association Task Force on Practice Guidelines (ACC/ AHA/SCAI Writing Committee to Update the 2001 Guidelines for Percutaneous Coronary Intervention). J Am Coll Cardio/ 2006; 47:e1-121.

56. Meijboom WB, Van Mieghem CA, van Pelt N, et al. Comprehensive assessment of coronary artery stenoses: computed tomography coronary angiography versus conventional coronary angiography and correlation with fractional flow reserve in patients with stable angina. J Am Coll Cardio/ 2008;52:636-43.

57. Tonino PA, De Bruyne B, Pijls NH, et al. Fractional flow reserve versus angiography for guiding percutaneous coronary intervention. N Engl J Med 2009;360:213-24.

58. Pijls NH, Fearon WF, Tonino PA, et al. Fractional flow reserve versus angiography for guiding percutaneous coronary intervention in patients with multivessel coronary artery disease: 2-year follow-up of the FAME (Fractional Flow Reserve Versus Angiography for Multivessel Evaluation) study. J Am Coll Cardiol 2010;56:177-84.

59. Hamon M, Fau G, Née G, Ehtisham J, Morello R, Hamon M. Metaanalysis of the diagnostic performance of stress perfusion cardiovascular magnetic resonance for detection of coronary artery disease. $J$ Cardiovasc Magn Reson 2010;12:29.

60. Rieber J, Huber A, Erhard I, et al. Cardiac magnetic resonance perfusion imaging for the functional assessment of coronary artery disease: a comparison with coronary angiography and fractional flow reserve. Eur Heart J 2006;27:1465-71.

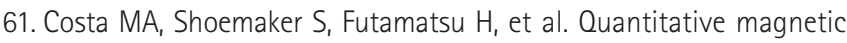
resonance perfusion imaging detects anatomic and physiologic coronary artery disease as measured by coronary angiography and fractional flow reserve. J Am Coll Cardiol 2007;50:514-22.

62. Watkins S, McGeoch R, Lyne J, et al. Validation of magnetic reso- 
nance myocardial perfusion imaging with fractional flow reserve for the detection of significant coronary heart disease. Circulation 2009; 120:2207-213.

63. Lockie $T$, Ishida $M$, Perera $D$, et al. High-resolution magnetic resonance myocardial perfusion imaging at 3.0-Tesla to detect hemodynamically significant coronary stenoses as determined by fractional flow reserve. J Am Coll Cardiol 2011;57:70-5.

64. Groothuis JG, Beek AM, Brinckman SL, et al. Combined non-invasive functional and anatomical diagnostic work-up in clinical practice: the magnetic resonance and computed tomography in suspected coronary artery disease (MARCC) study. Eur Heart J 2013;34:1990-8.

65. Jaarsma C, Leiner T, Bekkers SC, et al. Diagnostic performance of noninvasive myocardial perfusion imaging using single-photon emission computed tomography, cardiac magnetic resonance, and positron emission tomography imaging for the detection of obstructive coronary artery disease: a meta-analysis. J Am Coll Cardio/ 2012;59:1719-28.

66. Bryan AJ, Angelini GD. The biology of saphenous vein graft occlusion: etiology and strategies for prevention. Curr Opin Cardiol 1994; 9:641-9.

67. Barner HB, Standeven JW, Reese J. Twelve-year experience with internal mammary artery for coronary artery bypass. J Thorac Cardiovasc Surg 1985;90:668-75.

68. Cameron AA, Davis KB, Rogers WJ. Recurrence of angina after coronary artery bypass surgery: predictors and prognosis (CASS Registry). Coronary Artery Surgery Study. J Am Coll Cardiol 1995;26:895-9.

69. Langerak SE, Vliegen HW, de Roos A, et al. Detection of vein graft disease using high-resolution magnetic resonance angiography. Circulation 2002;105:328-33.

70. Galjee MA, van Rossum AC, Doesburg T, van Eenige MJ, Visser CA. Value of magnetic resonance imaging in assessing patency and function of coronary artery bypass grafts. An angiographically controlled study. Circulation 1996;93:660-6.

71. Duerinckx AJ, Atkinson D, Hurwitz R. Assessment of coronary artery patency after stent placement using magnetic resonance angiography. J Magn Reson Imaging 1998;8:896-902.

72. Sardanelli F, Zandrino F, Molinari G, lozzelli A, Balbi M, Barsotti A. MR evaluation of coronary stents with navigator echo and breath-hold cine gradient-echo techniques. Eur Radio/ 2002;12:193-200.

73. De Cobelli F, Cappio S, Vanzulli A, Del Maschio A. MRI assessment of coronary stents. Rays 1999;24:140-8.

74. Duerinckx AJ, Atkinson D, Hurwitz R, Mintorovitch J, Whitney W. Coronary MR angiography after coronary stent placement. AJR Am J Roentgenol 1995;165:662-4.

75. De Cobelli F, Guidetti D, Vanzulli A, Mellone R, Chierchia S, Del Maschio $A$. [Magnetic resonance angiography of coronary arteries: assessment in patients with coronary stenosis and control after stent positioning]. Radiol Med 1998;95:54-61.

76. Fleisher LA, Beckman JA, Brown KA, et al. ACC/AHA 2007 Guidelines on Perioperative Cardiovascular Evaluation and Care for Noncardiac Surgery: Executive Summary: A Report of the American College of Cardiology/American Heart Association Task Force on Practice Guidelines (Writing Committee to Revise the 2002 Guidelines on Perioperative Cardiovascular Evaluation for Noncardiac Surgery): Developed in
Collaboration With the American Society of Echocardiography, American Society of Nuclear Cardiology, Heart Rhythm Society, Society of Cardiovascular Anesthesiologists, Society for Cardiovascular Angiography and Interventions, Society for Vascular Medicine and Biology, and Society for Vascular Surgery. Circulation 2007;116:197196.

77. Fleisher LA, Beckman JA, Brown KA, et al. ACC/AHA 2007 guidelines on perioperative cardiovascular evaluation and care for noncardiac surgery: a report of the American College of Cardiology/American Heart Association Task Force on Practice Guidelines (Writing Committee to Revise the 2002 Guidelines on Perioperative Cardiovascular Evaluation for Noncardiac Surgery) developed in collaboration with the American Society of Echocardiography, American Society of Nuclear Cardiology, Heart Rhythm Society, Society of Cardiovascular Anesthesiologists, Society for Cardiovascular Angiography and Interventions, Society for Vascular Medicine and Biology, and Society for Vascular Surgery. J Am Coll Cardiol 2007;50:e159-241.

78. Fleisher LA; American College of Cardiology/American Heart Association. Cardiac risk stratification for noncardiac surgery: update from the American College of Cardiology/American Heart Association 2007 guidelines. Cleve Clin J Med 2009;76 Suppl 4:S9-15.

79. Freeman WK, Gibbons RJ. Perioperative cardiovascular assessment of patients undergoing noncardiac surgery. Mayo Clin Proc 2009;84: 79-90.

80. Holt NF. Perioperative cardiac risk reduction. Am Fam Physician 2012;85:239-46.

81. Nelson CL, Herndon JE, Mark DB, Pryor DB, Califf RM, Hlatky MA. Relation of clinical and angiographic factors to functional capacity as measured by the Duke Activity Status Index. Am J Cardiol 1991;68: 973-5.

82. Fathala $A$, Hassan W. Role of multimodality cardiac imaging in preoperative cardiovascular evaluation before noncardiac surgery. Ann Card Anaesth 2011;14:134-45.

83. Shah DJ, Kim HW, Kim RJ. Evaluation of ischemic heart disease. Heart Fail Clin 2009;5:315-32, v.

84. Mavrogeni S, Papadopoulos G, Karanasios E, Cokkinos DV. How to image Kawasaki disease: a validation of different imaging techniques. Int J Cardiol 2008;124:27-31.

85. Mavrogeni S, Papadopoulos G, Douskou M, et al. Magnetic resonance angiography is equivalent to $\mathrm{X}$-ray coronary angiography for the evaluation of coronary arteries in Kawasaki disease. J Am Coll Cardiol 2004;43:649-52.

86. Mavrogeni S, Papadopoulos G, Douskou M, et al. Magnetic resonance angiography, function and viability evaluation in patients with Kawasaki disease. J Cardiovasc Magn Reson 2006;8:493-8.

87. Greil GF, Stuber M, Botnar RM, et al. Coronary magnetic resonance angiography in adolescents and young adults with kawasaki disease. Circulation 2002;105:908-11.

88. Greil GF, Seeger A, Miller S, et al. Coronary magnetic resonance angiography and vessel wall imaging in children with Kawasaki disease. Pediatr Radio/ 2007;37:666-73.

89. Ferket BS, Genders TS, Colkesen EB, et al. Systematic review of guidelines on imaging of asymptomatic coronary artery disease. J Am Coll 
Cardio/ 2011;57:1591-600.

90. Choi KM, Kim RJ, Gubernikoff G, Vargas JD, Parker M, Judd RM. Transmural extent of acute myocardial infarction predicts long-term improvement in contractile function. Circulation 2001;104:1101-7.

91. Kim RJ, Wu E, Rafael A, et al. The use of contrast-enhanced magnetic resonance imaging to identify reversible myocardial dysfunction. $N$ Eng/ J Med 2000;343:1445-53.

92. Romero J, Kahan J, Kelesidis I, et al. CMR imaging for the evaluation of myocardial stunning after acute myocardial infarction: a metaanalysis of prospective trials. Eur Heart J Cardiovasc Imaging 2013;14: 1080-91.

93. Chan RH, Leung AA, Manning WJ. Prognostic utility of late gadolinium enhancement cardiac magnetic resonance imaging in coronary artery disease: a meta-analysis. J Cardiovasc Magn Reson 2013;15 Suppl 1: 075.

94. Romero J, Xue X, Gonzalez W, Garcia MJ. CMR imaging assessing viability in patients with chronic ventricular dysfunction due to coronary artery disease: a meta-analysis of prospective trials. JACC Cardiovasc Imaging 2012;5:494-508.

95. Trent RJ, Waiter GD, Hillis GS, McKiddie FI, Redpath TW, Walton S. Dobutamine magnetic resonance imaging as a predictor of myocardial functional recovery after revascularisation. Heart 2000;83:40-6.

96. Selvanayagam JB, Kardos A, Francis JM, et al. Value of delayed-enhancement cardiovascular magnetic resonance imaging in predicting myocardial viability after surgical revascularization. Circulation 2004; 110:1535-41.

97. Wagner A, Mahrholdt $H_{1}$ Holly TA, et al. Contrast-enhanced MRI and routine single photon emission computed tomography (SPECT) perfusion imaging for detection of subendocardial myocardial infarcts: an imaging study. Lancet 2003;361:374-9.

98. Roes SD, Kaandorp TA, Marsan NA, et al. Agreement and disagreement between contrast-enhanced magnetic resonance imaging and nuclear imaging for assessment of myocardial viability. Eur J Nucl Med Mol Imaging 2009;36:594-601.

99. Crean A, Khan SN, Davies LC, Coulden R, Dutka DP. Assessment of Myocardial Scar; Comparison Between F-FDG PET, CMR and Tc-Sestamibi. Clin Med Cardiol 2009;3:69-76.

100. Heijenbrok-Kal MH, Fleischmann KE, Hunink MG. Stress echocardiography, stress single-photon-emission computed tomography and electron beam computed tomography for the assessment of coronary artery disease: a meta-analysis of diagnostic performance. Am Heart J 2007;154:415-23.

101. Eitel I, Desch S, de Waha S, et al. Long-term prognostic value of myocardial salvage assessed by cardiovascular magnetic resonance in acute reperfused myocardial infarction. Heart 2011;97:2038-45.

102. Eitel I, Desch S, Fuernau G, et al. Prognostic significance and determinants of myocardial salvage assessed by cardiovascular magnetic resonance in acute reperfused myocardial infarction. J Am Coll Cardiol 2010;55:2470-9.

103. Selvanayagam JB, Porto I, Channon $K_{1}$ et al. Troponin elevation after percutaneous coronary intervention directly represents the extent of irreversible myocardial injury: insights from cardiovascular magnetic resonance imaging. Circulation 2005;111:1027-32.
104. McMurray JJ, Adamopoulos S, Anker SD, et al. ESC Guidelines for the diagnosis and treatment of acute and chronic heart failure 2012: The Task Force for the Diagnosis and Treatment of Acute and Chronic Heart Failure 2012 of the European Society of Cardiology. Developed in collaboration with the Heart Failure Association (HFA) of the ESC. Eur Heart J 2012;33:1787-847.

105. Fonseca $C$. Diagnosis of heart failure in primary care. Heart Fail Rev 2006;11:95-107.

106. Kelder JC, Cramer MJ, van Wijngaarden J, et al. The diagnostic value of physical examination and additional testing in primary care patients with suspected heart failure. Circulation 2011;124:2865-73.

107. Assomull RG, Shakespeare C, Kalra PR, et al. Role of cardiovascular magnetic resonance as a gatekeeper to invasive coronary angiography in patients presenting with heart failure of unknown etiology. Circulation 2011;124:1351-60.

108. Bellenger NG, Burgess MI, Ray SG, et al. Comparison of left ventricular ejection fraction and volumes in heart failure by echocardiography, radionuclide ventriculography and cardiovascular magnetic resonance; are they interchangeable? Eur Heart J 2000;21:1387-96.

109. Bristow MR, Gilbert EM, Abraham WT, et al. Carvedilol produces doserelated improvements in left ventricular function and survival in subjects with chronic heart failure. MOCHA Investigators. Circulation 1996;94:2807-16.

110. Capomolla S, Febo O, Gnemmi M, et al. Beta-blockade therapy in chronic heart failure: diastolic function and mitral regurgitation improvement by carvedilol. Am Heart J 2000;139:596-608.

111. Doughty RN, Whalley GA, Walsh HA, Gamble GD, López-Sendón J, Sharpe N; CAPRICORN Echo Substudy Investigators. Effects of carvedilol on left ventricular remodeling after acute myocardial infarction: the CAPRICORN Echo Substudy. Circulation 2004;109:201-6.

112. Alfakih $K_{1}$ Reid $S_{1}$ Jones T, Sivananthan M. Assessment of ventricular function and mass by cardiac magnetic resonance imaging. Eur Radiol 2004;14:1813-22.

113. Holman ER, Buller VG, de Roos A, et al. Detection and quantification of dysfunctional myocardium by magnetic resonance imaging. A new three-dimensional method for quantitative wall-thickening analysis. Circulation 1997;95: 924-31.

114. Grothues F, Moon JC, Bellenger NG, Smith GS, Klein HU, Pennell DJ. Interstudy reproducibility of right ventricular volumes, function, and mass with cardiovascular magnetic resonance. Am Heart J 2004;147: 218-23.

115. Grothues F, Smith GC, Moon JC, et al. Comparison of interstudy reproducibility of cardiovascular magnetic resonance with two-dimensional echocardiography in normal subjects and in patients with heart failure or left ventricular hypertrophy. Am J Cardiol 2002;90:29-34.

116. Jenkins C, Moir S, Chan J, Rakhit D, Haluska B, Marwick TH. Left ventricular volume measurement with echocardiography: a comparison of left ventricular opacification, three-dimensional echocardiography, or both with magnetic resonance imaging. Eur Heart J 2009;30:98106.

117. Bellenger NG, Davies LC, Francis JM, Coats AJ, Pennell DJ. Reduction in sample size for studies of remodeling in heart failure by the use of cardiovascular magnetic resonance. J Cardiovasc Magn Reson 2000; 
2:271-8.

118. Kim YJ, Kim RJ. The role of cardiac MR in new-onset heart failure. Curr Cardiol Rep 2011;13:185-93.

119. Valle-Muñoz A, Estornell-Erill J, Soriano-Navarro CJ, et al. Late gadolinium enhancement-cardiovascular magnetic resonance identifies coronary artery disease as the aetiology of left ventricular dysfunction in acute new-onset congestive heart failure. Eur J Echocardiogr 2009; 10:968-74.

120. Hamilton-Craig C, Strugnell WE, Raffel OC, Porto I, Walters DL, Slaughter RE. CT angiography with cardiac MRI: non-invasive functional and anatomical assessment for the etiology in newly diagnosed heart failure. Int J Cardiovasc Imaging 2012;28:1111-22.

121. Bluemke DA, Kronmal RA, Lima JA, et al. The relationship of left ventricular mass and geometry to incident cardiovascular events: the MESA (Multi-Ethnic Study of Atherosclerosis) study. J Am Coll Cardiol 2008;52:2148-55.

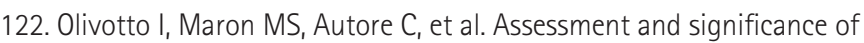
left ventricular mass by cardiovascular magnetic resonance in hypertrophic cardiomyopathy. J Am Coll Cardio/ 2008;52:559-66.

123. Follath $F$, Cleland JG, Klein W, Murphy R. Etiology and response to drug treatment in heart failure. J Am Coll Cardio/ 1998;32:1167-72.

124. Mahrholdt H, Wagner A, Judd RM, Sechtem U, Kim RJ. Delayed enhancement cardiovascular magnetic resonance assessment of nonischaemic cardiomyopathies. Eur Heart J 2005;26:1461-74.

125. Choudhury L, Mahrholdt H, Wagner A, et al. Myocardial scarring in asymptomatic or mildly symptomatic patients with hypertrophic cardiomyopathy. J Am Coll Cardio/ 2002;40:2156-64.

126. Kim KH, Kim HK, Hwang IC, et al. Myocardial scarring on cardiovascular magnetic resonance in asymptomatic or minimally symptomatic patients with "pure" apical hypertrophic cardiomyopathy. J Cardiovasc Magn Reson 2012;14:52.

127. Moon JC, Sachdev B, Elkington AG, et al. Gadolinium enhanced cardiovascular magnetic resonance in Anderson-Fabry disease. Evidence for a disease specific abnormality of the myocardial interstitium. Eur Heart J 2003;24:2151-5.

128. Maceira AM, Joshi J, Prasad SK, et al. Cardiovascular magnetic resonance in cardiac amyloidosis. Circulation 2005;111:186-93.

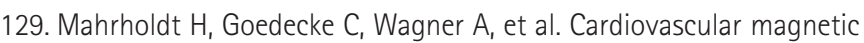
resonance assessment of human myocarditis: a comparison to histology and molecular pathology. Circulation 2004;109:1250-8.

130. Friedrich MG, Strohm O, Schulz-Menger J, Marciniak H, Luft FC, Dietz R. Contrast media-enhanced magnetic resonance imaging visualizes myocardial changes in the course of viral myocarditis. Circulation 1998;97:1802-9.

131. Klem I, Shah DJ, White RD, et al. Prognostic value of routine cardiac magnetic resonance assessment of left ventricular ejection fraction and myocardial damage: an international, multicenter study. Circ Cardiovasc Imaging 2011;4:610-9.

132. Klem I, Weinsaft JW, Bahnson TD, et al. Assessment of myocardial scarring improves risk stratification in patients evaluated for cardiac defibrillator implantation. J Am Coll Cardio/ 2012;60:408-20.

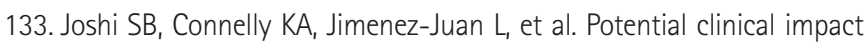
of cardiovascular magnetic resonance assessment of ejection frac- tion on eligibility for cardioverter defibrillator implantation. J Cardiovasc Magn Reson 2012;14:69.

134. Gao $P_{1}$ Yee $R$, Gula $L$, et al. Prediction of arrhythmic events in ischemic and dilated cardiomyopathy patients referred for implantable cardiac defibrillator: evaluation of multiple scar quantification measures for late gadolinium enhancement magnetic resonance imaging. Circ Cardiovasc Imaging 2012;5:448-56.

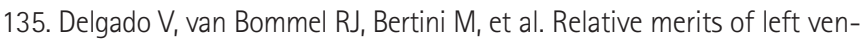
tricular dyssynchrony, left ventricular lead position, and myocardial scar to predict long-term survival of ischemic heart failure patients undergoing cardiac resynchronization therapy. Circulation 2011;123: 70-8.

136. Leyva F, Foley PW. Current and future role of cardiovascular magnetic resonance in cardiac resynchronization therapy. Heart Fail Rev 2011; 16:251-62.

137. Leyva F, Foley PW, Chalil S, et al. Cardiac resynchronization therapy guided by late gadolinium-enhancement cardiovascular magnetic resonance. J Cardiovasc Magn Reson 2011;13:29.

138. Dickfeld T, Tian J, Ahmad G, et al. MRI-Guided ventricular tachycardia ablation: integration of late gadolinium-enhanced 3D scar in patients with implantable cardioverter-defibrillators. Circ Arrhythm Electrophysiol 2011;4:172-84.

139. Junttila MJ, Fishman JE, Lopera GA, et al. Safety of serial MRI in patients with implantable cardioverter defibrillators. Heart 2011;97: 1852-6.

140. Chessa $M$, Carrozza $M$, Butera $G$, et al. Results and mid-long-term follow-up of stent implantation for native and recurrent coarctation of the aorta. Eur Heart J 2005;26:2728-32.

141. Hassan W, Awad M, Fawzy ME, et al. Long-term effects of balloon angioplasty on left ventricular hypertrophy in adolescent and adult patients with native coarctation of the aorta. Up to 18 years follow-up results. Catheter Cardiovasc Interv 2007;70:881-6.

142. Bogaert J, Kuzo R, Dymarkowski S, et al. Follow-up of patients with previous treatment for coarctation of the thoracic aorta: comparison between contrast-enhanced MR angiography and fast spin-echo MR imaging. Eur Radiol 2000;10:1847-54.

143. Geva T, Greil GF, Marshall AC, Landzberg M, Powell AJ. Gadoliniumenhanced 3-dimensional magnetic resonance angiography of pulmonary blood supply in patients with complex pulmonary stenosis or atresia: comparison with x-ray angiography. Circulation 2002;106: 473-8.

144. Prasad SK, Soukias N, Hornung T, et al. Role of magnetic resonance angiography in the diagnosis of major aortopulmonary collateral arteries and partial anomalous pulmonary venous drainage. Circulation 2004;109:207-14.

145. Fattori R, Bacchi Reggiani L, Pepe C, et al. Magnetic resonance imaging evaluation of aortic elastic properties as early expression of Marfan syndrome. J Cardiovasc Magn Reson 2000;2:251-6.

146. Baumgartner D, Baumgartner C, Mátyás G, et al. Diagnostic power of aortic elastic properties in young patients with Marfan syndrome. J Thorac Cardiovasc Surg 2005;129:730-9.

147. Geva T, Vick GW 3rd, Wendt RE, Rokey R. Role of spin echo and cine magnetic resonance imaging in presurgical planning of heterotaxy 
syndrome. Comparison with echocardiography and catheterization. Circulation 1994;90:348-56.

148. Salehian O, Schwerzmann M, Merchant N, Webb GD, Siu SC, Therrien $\mathrm{J}$. Assessment of systemic right ventricular function in patients with transposition of the great arteries using the myocardial performance index: comparison with cardiac magnetic resonance imaging. Circulation 2004;110:3229-33.

149. Warnes CA. Transposition of the great arteries. Circulation 2006;114: 2699-709.

150. Rutledge JM, Nihill MR, Fraser CD, Smith OE, McMahon CJ, Bezold LI. Outcome of 121 patients with congenitally corrected transposition of the great arteries. Pediatr Cardio/ 2002;23:137-45.

151. Didier D, Higgins CB. Identification and localization of ventricular septal defect by gated magnetic resonance imaging. Am J Cardio/ 1986; 57:1363-8.

152. Hundley WG, Li HF, Lange RA, et al. Assessment of left-to-right intracardiac shunting by velocity-encoded, phase-difference magnetic resonance imaging. A comparison with oximetric and indicator dilution techniques. Circulation 1995;91: 2955-60.

153. Körperich $H_{1}$ Gieseke J, Barth $P_{1}$ et al. Flow volume and shunt quantification in pediatric congenital heart disease by real-time magnetic resonance velocity mapping: a validation study. Circulation 2004;109: 1987-93.

154. Beerbaum $P_{1}$ Körperich $H_{1}$ Gieseke J, Barth $P$, Peuster M, Meyer H. Rapid left-to-right shunt quantification in children by phase-contrast magnetic resonance imaging combined with sensitivity encoding (SENSE). Circulation 2003;108:1355-61.

155. American College of Cardiology; American Heart Association Task Force on Practice Guidelines (Writing Committee to revise the 1998 guidelines for the management of patients with valvular heart disease); Society of Cardiovascular Anesthesiologists, Bonow RO, et al. ACC/AHA 2006 guidelines for the management of patients with valvular heart disease: a report of the American College of Cardiologyl American Heart Association Task Force on Practice Guidelines (writing Committee to Revise the 1998 guidelines for the management of patients with valvular heart disease) developed in collaboration with the Society of Cardiovascular Anesthesiologists endorsed by the Society for Cardiovascular Angiography and Interventions and the Society of Thoracic Surgeons. J Am Coll Cardiol 2006;48:e1-148.

156. Rebergen SA, Chin JG, Ottenkamp J, van der Wall EE, de Roos A. Pulmonary regurgitation in the late postoperative follow-up of tetralogy of Fallot. Volumetric quantitation by nuclear magnetic resonance velocity mapping. Circulation 1993;88:2257-66.

157. Apitz C, Webb GD, Redington AN. Tetralogy of Fallot. Lancet 2009; 374:1462-71.

158. Therrien J, Provost Y, Merchant N, Williams W, Colman J, Webb G. Optimal timing for pulmonary valve replacement in adults after tetralogy of Fallot repair. Am J Cardio/ 2005;95:779-82.

159. Oosterhof T, van Straten A, Vliegen HW, et al. Preoperative thresholds for pulmonary valve replacement in patients with corrected tetralogy of Fallot using cardiovascular magnetic resonance. Circulation 2007; 116:545-51.

160. Babu-Narayan SV, Kilner PJ, Li W, et al. Ventricular fibrosis suggested by cardiovascular magnetic resonance in adults with repaired tetralogy of fallot and its relationship to adverse markers of clinical outcome. Circulation 2006;113:405-13.

161. Attenhofer Jost CH, Edmister WD, Julsrud PR, et al. Prospective comparison of echocardiography versus cardiac magnetic resonance imaging in patients with Ebstein's anomaly. Int J Cardiovasc Imaging 2012;28:1147-59.

162. Yalonetsky S, Tobler D, Greutmann $M$, et al. Cardiac magnetic resonance imaging and the assessment of ebstein anomaly in adults. Am J Cardiol 2011;107:767-73.

163. Lemmer J, Heise $G$, Rentzsch $A$, et al. Right ventricular function in grown-up patients after correction of congenital right heart disease. Clin Res Cardiol 2011;100:289-96.

164. Grothoff M, Spors B, Abdul-Khaliq H, Gutberlet M. Evaluation of postoperative pulmonary regurgitation after surgical repair of tetralogy of Fallot: comparison between Doppler echocardiography and MR velocity mapping. Pediatr Radio/ 2008;38:186-91.

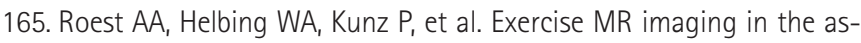
sessment of pulmonary regurgitation and biventricular function in patients after tetralogy of fallot repair. Radiology 2002;223:204-11.

166. Oosterhof T, Mulder BJ, Vliegen HW, de Roos A. Cardiovascular magnetic resonance in the follow-up of patients with corrected tetralogy of Fallot: a review. Am Heart J 2006;151:265-72.

167. Oosterhof T, Mulder BJ, Vliegen HW, de Roos A. Corrected tetralogy of Fallot: delayed enhancement in right ventricular outflow tract. Radiology 2005;237:868-71.

168. Davlouros PA, Kilner PJ, Hornung TS, et al. Right ventricular function in adults with repaired tetralogy of Fallot assessed with cardiovascular magnetic resonance imaging: detrimental role of right ventricular outflow aneurysms or akinesia and adverse right-to-left ventricular interaction. J Am Coll Cardio/ 2002;40:2044-52.

169. Taylor AM, Dymarkowski S, Hamaekers $P$, et al. MR coronary angiography and late-enhancement myocardial MR in children who underwent arterial switch surgery for transposition of great arteries. Radiology 2005;234:542-7.

170. Garg R, Powell AJ, Sena L, Marshall AC, Geva T. Effects of metallic implants on magnetic resonance imaging evaluation of Fontan palliation. Am J Cardio/ 2005;95:688-91.

171. Grosse-Wortmann L, Al-Otay A, Yoo SJ. Aortopulmonary collaterals after bidirectional cavopulmonary connection or Fontan completion: quantification with MRI. Circ Cardiovasc Imaging 2009;2:219-25.

172. Fogel MA, Weinberg PM, Chin AJ, Fellows KE, Hoffman EA. Late ventricular geometry and performance changes of functional single ventricle throughout staged Fontan reconstruction assessed by magnetic resonance imaging. J Am Coll Cardiol 1996;28:212-21.

173. Cawley PJ, Maki JH, Otto CM. Cardiovascular magnetic resonance imaging for valvular heart disease: technique and validation. Circulation 2009;119:468-78.

174. Søndergaard L, Hildebrandt P, Lindvig K, et al. Valve area and cardiac output in aortic stenosis: quantification by magnetic resonance velocity mapping. Am Heart J 1993;126: 156-64.

175. Caruthers SD, Lin SJ, Brown P, et al. Practical value of cardiac magnetic resonance imaging for clinical quantification of aortic valve ste- 
nosis: comparison with echocardiography. Circulation 2003;108:223643.

176. Djavidani $B$, Debl $K$, Lenhart $M$, et al. Planimetry of mitral valve stenosis by magnetic resonance imaging. J Am Coll Cardio/ 2005;45:204853.

177. Honda N, Machida K, Hashimoto M, et al. Aortic regurgitation: quantitation with MR imaging velocity mapping. Radiology 1993;186: 189-94.

178. Ley S, Eichhorn J, Ley-Zaporozhan J, et al. Evaluation of aortic regurgitation in congenital heart disease: value of MR imaging in comparison to echocardiography. Pediatr Radio/ 2007;37:426-36.

179. Kon MW, Myerson SG, Moat NE, Pennell DJ. Quantification of regurgitant fraction in mitral regurgitation by cardiovascular magnetic resonance: comparison of techniques. J Heart Valve Dis 2004;13:600-7.

180. Cawley PJ, Hamilton-Craig C, Owens DS, et al. Prospective comparison of valve regurgitation quantitation by cardiac magnetic resonance imaging and transthoracic echocardiography. Circ Cardiovasc Imaging 2013;6:48-57.

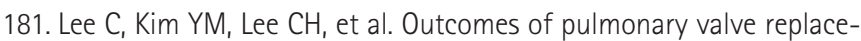
ment in 170 patients with chronic pulmonary regurgitation after relief of right ventricular outflow tract obstruction: implications for optimal timing of pulmonary valve replacement. J Am Coll Cardiol 2012;60:1005-14.

182. Sarikouch S, Koerperich H, Dubowy KO, et al. Impact of gender and age on cardiovascular function late after repair of tetralogy of Fallot: percentiles based on cardiac magnetic resonance. Circ Cardiovasc Imaging 2011;4:703-11.

183. Mercer-Rosa L, Yang W, Kutty S, Rychik J, Fogel M, Goldmuntz E. Quantifying pulmonary regurgitation and right ventricular function in surgically repaired tetralogy of Fallot: a comparative analysis of echocardiography and magnetic resonance imaging. Circ Cardiovasc Imaging 2012;5:637-43.

184. Koca B, Öztunç F, Eroğlu AG, Gökalp S, Dursun M, Yilmaz R. Evaluation of right ventricular function in patients with tetralogy of Fallot using the myocardial performance index and isovolumic acceleration: a comparison with cardiac magnetic resonance imaging. Cardiol Young 2014;24:422-9.

185. Botnar R, Nagel E, Scheidegger MB, Pedersen EM, Hess O, Boesiger P. Assessment of prosthetic aortic valve performance by magnetic resonance velocity imaging. MAGMA 2000;10:18-26.

186. Kozerke S, Hasenkam JM, Nygaard H, Paulsen PK, Pedersen EM, Boesiger P. Heart motion-adapted MR velocity mapping of blood velocity distribution downstream of aortic valve prostheses: initial experience. Radiology 2001;218:548-55.

187. von Knobelsdorff-Brenkenhoff $F$, Rudolph A, Wassmuth $R$, et al. Feasibility of cardiovascular magnetic resonance to assess the orifice area of aortic bioprostheses. Circ Cardiovasc Imaging 2009;2:397-404.

188. Marcus Fl, McKenna WJ, Sherrill D, et al. Diagnosis of arrhythmogenic right ventricular cardiomyopathy/dysplasia: proposed modification of the Task Force Criteria. Eur Heart J 2010;31:806-14.

189. Sen-Chowdhry S, Prasad SK, Syrris P, et al. Cardiovascular magnetic resonance in arrhythmogenic right ventricular cardiomyopathy revisited: comparison with task force criteria and genotype. J Am Coll Car- dio/ 2006;48:2132-40.

190. Keller DI, Osswald S, Bremerich J, et al. Arrhythmogenic right ventricular cardiomyopathy: diagnostic and prognostic value of the cardiac MRI in relation to arrhythmia-free survival. Int J Cardiovasc Imaging 2003;19:537-43; discussion 545-7.

191. Tandri H, Saranathan M, Rodriguez ER, et al. Noninvasive detection of myocardial fibrosis in arrhythmogenic right ventricular cardiomyopathy using delayed-enhancement magnetic resonance imaging. J Am Coll Cardio/ 2005;45:98-103.

192. Hosch W, Kristen AV, Libicher M, et al. Late enhancement in cardiac amyloidosis: correlation of MRI enhancement pattern with histopathological findings. Amyloid 2008;15:196-204.

193. Vogelsberg H, Mahrholdt H, Deluigi CC, et al. Cardiovascular magnetic resonance in clinically suspected cardiac amyloidosis: noninvasive imaging compared to endomyocardial biopsy. J Am Coll Cardiol 2008; 51:1022-30.

194. Syed IS, Glockner JF, Feng D, et al. Role of cardiac magnetic resonance imaging in the detection of cardiac amyloidosis. JACC Cardiovasc Imaging 2010;3:155-64.

195. Shimada T, Shimada K, Sakane T, et al. Diagnosis of cardiac sarcoidosis and evaluation of the effects of steroid therapy by gadoliniumDTPA-enhanced magnetic resonance imaging. Am J Med 2001;110: 520-7.

196. Fallah-Rad N, Walker JR, Wassef A, et al. The utility of cardiac biomarkers, tissue velocity and strain imaging, and cardiac magnetic resonance imaging in predicting early left ventricular dysfunction in patients with human epidermal growth factor receptor II-positive breast cancer treated with adjuvant trastuzumab therapy. J Am Coll Cardiol 2011;57:2263-70.

197. Oechslin EN, Attenhofer Jost CH, Rojas JR, Kaufmann PA, Jenni R. Long-term follow-up of 34 adults with isolated left ventricular noncompaction: a distinct cardiomyopathy with poor prognosis. J Am Coll Cardio/ 2000;36:493-500.

198. Petersen SE, Selvanayagam JB, Wiesmann F, et al. Left ventricular non-compaction: insights from cardiovascular magnetic resonance imaging. J Am Coll Cardio/ 2005;46:101-5.

199. Sharkey SW, Lesser JR, Zenovich AG, et al. Acute and reversible cardiomyopathy provoked by stress in women from the United States. Circulation 2005;111:472-9.

200. Haghi D, Fluechter S, Suselbeck T, Kaden JJ, Borggrefe M, Papavassiliu T. Cardiovascular magnetic resonance findings in typical versus atypical forms of the acute apical ballooning syndrome (Takotsubo cardiomyopathy). Int J Cardiol 2007;120:205-11.

201. Mitchell JH, Hadden TB, Wilson JM, Achari A, Muthupillai R, Flamm $S D$. Clinical features and usefulness of cardiac magnetic resonance imaging in assessing myocardial viability and prognosis in Takotsubo cardiomyopathy (transient left ventricular apical ballooning syndrome). Am J Cardio/ 2007;100:296-301.

202. Monney PA, Sekhri N, Burchell T, et al. Acute myocarditis presenting as acute coronary syndrome: role of early cardiac magnetic resonance in its diagnosis. Heart 2011;97:1312-8.

203. Jeserich $M$, Brunner $E_{1}$ Kandolf $R$, et al. Diagnosis of viral myocarditis by cardiac magnetic resonance and viral genome detection in periph- 
eral blood. Int J Cardiovasc Imaging 2013;29:121-9.

204. Marian AJ, Roberts R. The molecular genetic basis for hypertrophic cardiomyopathy. J Mo/ Cell Cardio/ 2001;33:655-70.

205. Rickers C, Wilke NM, Jerosch-Herold M, et al. Utility of cardiac magnetic resonance imaging in the diagnosis of hypertrophic cardiomyopathy. Circulation 2005;112:855-61.

206. Maron MS, Lesser JR, Maron BJ. Management implications of massive left ventricular hypertrophy in hypertrophic cardiomyopathy significantly underestimated by echocardiography but identified by cardiovascular magnetic resonance. Am J Cardiol 2010;105:1842-3.

207. Moon JC, Fisher NG, McKenna WJ, Pennell DJ. Detection of apical hypertrophic cardiomyopathy by cardiovascular magnetic resonance in patients with non-diagnostic echocardiography. Heart 2004;90: 645-9.

208. Maron MS, Maron BJ, Harrigan C, et al. Hypertrophic cardiomyopathy phenotype revisited after 50 years with cardiovascular magnetic resonance. J Am Coll Cardio/ 2009;54:220-8.

209. Adabag AS, Maron BJ, Appelbaum E, et al. Occurrence and frequency of arrhythmias in hypertrophic cardiomyopathy in relation to delayed enhancement on cardiovascular magnetic resonance. J Am Coll Cardiol 2008;51:1369-74.

210. Minami Y, Kajimoto K, Terajima Y, et al. Clinical implications of midventricular obstruction in patients with hypertrophic cardiomyopathy. J Am Coll Cardio/ 2011;57:2346-55.

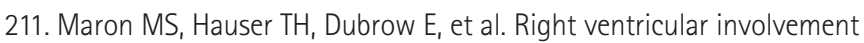
in hypertrophic cardiomyopathy. Am J Cardio/ 2007;100:1293-8.

212. Rudolph A, Abdel-Aty $H$, Bohl $S$, et al. Noninvasive detection of fibrosis applying contrast-enhanced cardiac magnetic resonance in different forms of left ventricular hypertrophy relation to remodeling. J Am Coll Cardiol 2009;53:284-91.

213. Moravsky G, Ofek E, Rakowski H, et al. Myocardial fibrosis in hypertrophic cardiomyopathy: accurate reflection of histopathological findings by CMR. JACC Cardiovasc Imaging 2013;6:587-96.

214. Flett $A S$, Hasleton J, Cook $C$, et al. Evaluation of techniques for the quantification of myocardial scar of differing etiology using cardiac magnetic resonance. JACC Cardiovasc Imaging 2011;4:150-6.

215. Moon JC, Reed E, Sheppard MN, et al. The histologic basis of late gadolinium enhancement cardiovascular magnetic resonance in hypertrophic cardiomyopathy. J Am Coll Cardio/ 2004;43:2260-4.

216. O'Hanlon $R$, Grasso $A$, Roughton $M$, et al. Prognostic significance of myocardial fibrosis in hypertrophic cardiomyopathy. J Am Coll Cardiol 2010;56:867-74.

217. Bruder 0 , Wagner $A$, Jensen $C J$, et al. Myocardial scar visualized by cardiovascular magnetic resonance imaging predicts major adverse events in patients with hypertrophic cardiomyopathy. J Am Coll Cardiol 2010;56:875-87.

218. Ismail TF, Prasad SK, Pennell DJ. Prognostic importance of late gadolinium enhancement cardiovascular magnetic resonance in cardiomyopathy. Heart 2012;98:438-42.

219. Maron MS, Appelbaum E, Harrigan CJ, et al. Clinical profile and significance of delayed enhancement in hypertrophic cardiomyopathy. Circ Heart Fail 2008;1:184-91.

220. Rubinshtein R, Glockner JF, Ommen SR, et al. Characteristics and clinical significance of late gadolinium enhancement by contrast-enhanced magnetic resonance imaging in patients with hypertrophic cardiomyopathy. Circ Heart Fail 2010;3:51-8.

221. Green JJ, Berger JS, Kramer CM, Salerno M. Prognostic value of late gadolinium enhancement in clinical outcomes for hypertrophic cardiomyopathy. JACC Cardiovasc Imaging 2012;5:370-7.

222. Moon JC, McKenna WJ, McCrohon JA, Elliott PM, Smith GC, Pennell DJ. Toward clinical risk assessment in hypertrophic cardiomyopathy with gadolinium cardiovascular magnetic resonance. J Am Coll Cardiol 2003;41:1561-7.

223. Fluechter S, Kuschyk J, Wolpert C, et al. Extent of late gadolinium enhancement detected by cardiovascular magnetic resonance correlates with the inducibility of ventricular tachyarrhythmia in hypertrophic cardiomyopathy. J Cardiovasc Magn Reson 2010;12:30.

224. To AC, Dhillon A, Desai MY. Cardiac magnetic resonance in hypertrophic cardiomyopathy. JACC Cardiovasc Imaging 2011;4:1123-37.

225. Germans T, Wilde AA, Dijkmans PA, et al. Structural abnormalities of the inferoseptal left ventricular wall detected by cardiac magnetic resonance imaging in carriers of hypertrophic cardiomyopathy mutations. J Am Coll Cardio/ 2006;48:2518-23.

226. Maron MS, Rowin EJ, Lin D, et al. Prevalence and clinical profile of myocardial crypts in hypertrophic cardiomyopathy. Circ Cardiovasc Imaging 2012:5:441-7.

227. Maron MS, Olivotto I, Harrigan $C_{\text {, et al. Mitral valve abnormalities }}$ identified by cardiovascular magnetic resonance represent a primary phenotypic expression of hypertrophic cardiomyopathy. Circulation 2011;124:40-7.

228. Rowin EJ, Maron MS, Lesser JR, Maron BJ. CMR with late gadolinium enhancement in genotype positive-phenotype negative hypertrophic cardiomyopathy. JACC Cardiovasc Imaging 2012;5:119-22.

229. Weinsaft JW, Kim HW, Crowley AL, et al. LV thrombus detection by routine echocardiography: insights into performance characteristics using delayed enhancement CMR. JACC Cardiovasc Imaging 2011;4: 702-12.

230. Mollet NR, Dymarkowski S, Volders W, et al. Visualization of ventricular thrombi with contrast-enhanced magnetic resonance imaging in patients with ischemic heart disease. Circulation 2002;106:2873-6.

231. Hong YJ, Hur J, Kim YJ, et al. The usefulness of delayed contrast-enhanced cardiovascular magnetic resonance imaging in differentiating cardiac tumors from thrombi in stroke patients. Int J Cardiovasc Imaging 2011;27 Suppl 1:89-95.

232. Weinsaft JW, Kim RJ, Ross M, et al. Contrast-enhanced anatomic imaging as compared to contrast-enhanced tissue characterization for detection of left ventricular thrombus. JACC Cardiovasc Imaging 2009; 2:969-79.

233. Motwani M, Kidambi A, Herzog BA, Uddin A, Greenwood JP, Plein S. MR imaging of cardiac tumors and masses: a review of methods and clinical applications. Radiology 2013;268:26-43.

234. Fieno DS, Saouaf $R$, Thomson LE, Abidov A, Friedman JD, Berman DS. Cardiovascular magnetic resonance of primary tumors of the heart: a review. J Cardiovasc Magn Reson 2006;8:839-53.

235. Gulati G, Sharma S, Kothari SS, Juneja R, Saxena A, Talwar KK. Comparison of echo and MRI in the imaging evaluation of intracardiac 
masses. Cardiovasc Intervent Radiol 2004;27:459-69.

236. Francone M, Dymarkowski S, Kalantzi M, Rademakers FE, Bogaert J. Assessment of ventricular coupling with real-time cine MRI and its value to differentiate constrictive pericarditis from restrictive cardiomyopathy. Eur Radiol 2006;16:944-51.

237. Mastouri R, Sawada SG, Mahenthiran J. Noninvasive imaging techniques of constrictive pericarditis. Expert Rev Cardiovasc Ther 2010;8: 1335-47.

238. Zurick AO, Bolen MA, Kwon DH, et al. Pericardial delayed hyperenhancement with CMR imaging in patients with constrictive pericarditis undergoing surgical pericardiectomy: a case series with histopathological correlation. JACC Cardiovasc Imaging 2011;4:1180-91.

239. Axel L. Assessment of pericardial disease by magnetic resonance and computed tomography. J Magn Reson Imaging 2004;19:816-26.

240. Shiga T, Wajima Z, Apfel CC, Inoue T, Ohe Y. Diagnostic accuracy of transesophageal echocardiography, helical computed tomography, and magnetic resonance imaging for suspected thoracic aortic dissection: systematic review and meta-analysis. Arch Intern Med 2006;166: 1350-6.

241. Lacomis JM, Pealer K, Fuhrman CR, Barley D, Wigginton W, Schwartzman D. Direct comparison of computed tomography and magnetic resonance imaging for characterization of posterior left atrial morphology. J Interv Card Electrophysio/ 2006;16:7-13.

242. Kato $R$, Lickfett $L$, Meininger $G$, et al. Pulmonary vein anatomy in pa- tients undergoing catheter ablation of atrial fibrillation: lessons learned by use of magnetic resonance imaging. Circulation 2003;107:2004-10.

243. Mansour M, Refaat $M$, Heist EK, et al. Three-dimensional anatomy of the left atrium by magnetic resonance angiography: implications for catheter ablation for atrial fibrillation. J Cardiovasc Electrophysiol 2006;17:719-23.

244. Durongpisitkul K, Tang NL, Soongswang J, Laohaprasitiporn D, Nana A, Kangkagate $\mathrm{C}$. Cardiac magnetic resonance imaging of atrial septal defect for transcatheter closure. J Med Assoc Thai 2002;85 Suppl 2: S658-66.

245. Weber C, Weber M, Ekinci O, et al. Atrial septal defects type II: noninvasive evaluation of patients before implantation of an Amplatzer Septal Occluder and on follow-up by magnetic resonance imaging compared with TEE and invasive measurement. Eur Radio/ 2008;18: 2406-13.

246. Thomson LE, Crowley AL, Heitner JF, et al. Direct en face imaging of secundum atrial septal defects by velocity-encoded cardiovascular magnetic resonance in patients evaluated for possible transcatheter closure. Circ Cardiovasc Imaging 2008;1:31-40.

247. La Manna A, Sanfilippo A, Capodanno D, et al. Cardiovascular magnetic resonance for the assessment of patients undergoing transcatheter aortic valve implantation: a pilot study. J Cardiovasc Magn Reson 2011;13:82. 